\title{
Mineralogy of iron microbial mats from Loihi Seamount
}

\section{Brandy M. Toner ${ }^{1}{ }^{*}$, Thelma S. Berquó ${ }^{2,3}$, F. Marc Michel ${ }^{4}$, Jeffry V. Sorensen ${ }^{1}$, Alexis S. Templeton ${ }^{5}$ and Katrina J. Edwards ${ }^{6,7}$}

${ }^{1}$ Department of Soil, Water, and Climate, University of Minnesota-Twin Cities, St. Paul, MN, USA

${ }^{2}$ Department of Earth Sciences, Institute for Rock Magnetism, University of Minnesota-Twin Cities, Minneapolis, MN, USA

${ }^{3}$ Physics Department, Concordia College, Moorhead, MN, USA

${ }^{4}$ SLAC National Accelerator Laboratory, Department of Geological and Environmental Sciences, Stanford University, Stanford, CA, USA

${ }^{5}$ Department of Geological Sciences, University of Colorado-Boulder, Boulder, CO, USA

${ }^{6}$ Department of Biological Sciences, University of Southern California, Los Angeles, CA, USA

7 Department of Earth Sciences, University of Southern California, Los Angeles, CA, USA

\section{Edited by:}

David Emerson, Bigelow Laboratory for Ocean Sciences, USA

Reviewed by:

John Stolz, Duquesne University, USA Jeffrey G. Catalano, Washington

University in St. Louis, USA

\section{*Correspondence:}

Brandy M. Toner, Department of Soil, Water, and Climate, University of Minnesota-Twin Cities, 1991 Upper Buford Circle, 439 Borlaug Hall, St. Paul, MN, USA

e-mail: toner@umn.edu
Extensive mats of Fe oxyhydroxides and associated Fe-oxidizing microbial organisms form in diverse geochemical settings - freshwater seeps to deep-sea vents - where ever opposing Fe(II)-oxygen gradients prevail. The mineralogy, reactivity, and structural transformations of Fe oxyhydroxides precipitated from submarine hydrothermal fluids within microbial mats remains elusive in active and fossil systems. In response, a study of Fe microbial mat formation at the Loihi Seamount was conducted to describe the physical and chemical characteristics of Fe-phases using extended X-ray absorption fine structure spectroscopy, powder X-ray diffraction, synchrotron radiation X-ray total scattering, low-temperature magnetic measurements, and Mössbauer spectroscopy. Particle sizes of $3.5-4.6 \mathrm{~nm}$ were estimated from magnetism data, and coherent scattering domain (CSD) sizes as small as $1.6 \mathrm{~nm}$ are indicated by pair distribution function (PDF) analysis. Disorder in the nanostructured Fe-bearing phases results in limited intermediate-range structural order: less than that of standard two-line ferrihydrite (Fh), except for the Pohaku site. The short-range ordered natural $\mathrm{Fh}\left(\mathrm{Fh}_{\mathrm{SRO}}\right)$ phases were stable at $4^{\circ} \mathrm{C}$ in the presence of oxygen for at least 1 year and during $400^{\circ} \mathrm{C}$ treatment. The observed stability of the $\mathrm{Fh}_{\mathrm{SRO}}$ is consistent with magnetic observations that point to non-interacting nanoparticles. PDF analyses of total scattering data provide further evidence for $\mathrm{Fh}_{\mathrm{SRO}}$ particles with a poorly ordered silica coating. The presence of coated particles explains the small CSD for the mat minerals, as well as the stability of the minerals over time and against heating. The mineral properties observed here provide a starting point from which progressively older and more extensively altered Fe deposits may be examined, with the ultimate goal of improved interpretation of past biogeochemical conditions and diagenetic processes.

Keywords: EXAFS, total X-ray scattering, Mössbauer, magnetism, microbial mat, Loihi Seamount, biomineral, nanoparticle

\section{INTRODUCTION}

Iron $(\mathrm{Fe})$ microbial mats form in opposing iron and oxygen gradients in a wide variety of settings (Emerson and Revsbech, 1994; Chan et al., 2004; Rentz et al., 2007; Druschel et al., 2008; Edwards et al., 2011). The physical and chemical properties of the Febearing phases will determine the biogeochemical reactivity of the minerals within the mats (Ekstrom et al., 2010; Boland et al., 2011; Hansel et al., 2011). Yet the crystallinity, local Fe coordination environment, and available reactive sites of the minerals are difficult to measure, and the structure or continuum of structures that compose one of the most common Fe oxyhydroxides, ferrihydrite (Fh), is an active topic of research and scientific controversy today (Michel et al., 2007a, 2010; Penn, 2007; Manceau, 2009, 2011; Pinney et al., 2009; Maillot et al., 2011), as it has been for more than two decades (Campbell, 1991; Drits et al., 1993; Manceau and Drits, 1993; Waychunas et al., 1996; Jambor and Dutrizac, 1998; Janney et al., 2000; Schwertmann et al., 2004). Poorly crystalline iron oxyhydroxides are often difficult to characterize due to nanometer particle dimensions (Michel et al., 2007a; Hochella Jr. et al., 2008) and a large number of polymorphs (Navrotsky et al., 2008). In addition, structural and compositional variability and complexity is intrinsic to Fe oxyhydroxides formed in settings such as microbial biofilms (Edwards et al., 2003; Chan et al., 2004; Toner et al., 2009) or in the presence of strongly sorbing inorganic and organic ligands (Cornell and Schwertmann, 1979; Waychunas et al., 1996; Rose et al., 1997; Vilge-Ritter et al., 1999; Doelsch et al., 2003; Mikutta, 2011). Considering that the gold standard measurement for mineralogy - powder X-ray diffraction (XSD) - relies on long-range structural order, it is not surprising that Fe mineralogy of microbial mats, often formed in the presence of abundant inorganic ligands and microbial cell surfaces and exudates, remains elusive. One viable strategy for describing $\mathrm{Fe}$ microbial mat mineralogy is to measure a suite of fundamental properties: (1) short-range structural order and valence state; (2) degree of structural defects relative to standard synthetic minerals; (3) degree of particle interaction and aggregation; 
(4) distribution of particle dimensions and extent of structural coherence; and (5) stability and recrystallization as a function of time and temperature.

In this context, the mineralogy of Loihi Seamount Fe microbial mats was examined as a function of temperature, water depth, and bulk aqueous geochemistry. Loihi Seamount is a seismically active submarine volcano and emerging Hawaiian Island (Klein, 1982; DeCarlo et al., 1983). Hydrothermal venting at Loihi produces opposing Fe and oxygen gradients (Glazer and Rouxel, 2009) and supports abundant microbial life including Fe-oxidizing bacteria (Emerson and Moyer, 2002). Iron mat formation at Loihi is pervasive, occurring at a range of temperatures $\left(0-60^{\circ} \mathrm{C}\right)$, in diverse settings (ultra-diffuse regional venting at $5000 \mathrm{~m}$ to focused venting as shallow as $1116 \mathrm{~m}$ ), and microbial activity in the mats has been demonstrated (Moyer et al., 1994, 1995; Emerson and Moyer, 2002; Edwards et al., 2011). Filamentous, non-filamentous, tubular, and branching microbial structures in the mats that form near venting are encrusted with Fe minerals, and biological Fe oxidation contributes approximately $60 \%$ of total Fe oxidation (Karl et al., 1988, 1989; Emerson and Moyer, 2002). Vent fluids near the summit of Loihi are enriched in carbon dioxide, ammonium, silicon (Si), Fe, and manganese (Mn) (Sedwick et al., 1992; Wheat et al., 2000). The goal of this research is to describe the physical and chemical properties of the minerals formed in Loihi Fe microbial mats. To accomplish this, we used synchrotron radiation X-ray absorption spectroscopy, X-ray fluorescence microspectroscopy, and X-ray total scattering, as well as Mössbauer spectroscopy and low-temperature magnetic measurements to identify the factors contributing to mat mineralogy. We also examine whether biogeochemical factors that control mineral formation influence only the initial precipitation of Fe oxyhydroxides or their long-term properties and preservation.

\section{MATERIALS AND METHODS LOIHI MAT COLLECTION AND STORAGE}

Iron microbial mats at the Loihi Seamount were collected during research cruises in 2006 (R/V Melville), 2007 (R/V Kilo Moana), and 2008 (R/V Thompson) as part of a National Science Foundation Fe Microbial Observatory (FeMO) project. General characteristics of each site are summarized in Table 1 . Sites represent the range of naturally occurring characteristics of the vents that occur at Loihi.

The remotely operated vehicle JASON2 was used to collect mats with scoops and suction samplers. Typically the samples collected by slurp suction sampling experience a vigorous mixing of a large volume (several liters) of mat material, whereas consolidated mats collected in polycarbonate scoops retain some of their structural cohesiveness. Once shipboard, the loosely aggregated, well-mixed mat "flocs" were sub-sampled into $15 \mathrm{~mL}$ sterile tubes and either: (1) stored at $4^{\circ} \mathrm{C}$ and referred to as "fresh" or "aged" mat samples; or (2) frozen at $-20^{\circ} \mathrm{C}$ and referred to as "frozen" mat samples. In the laboratory, a subset of these flocculent mat samples were defrosted, rinsed with purified water to remove sea salts, and dried at $40^{\circ} \mathrm{C}$ : these samples are referred to as (3) "dry" mat samples. At the deepest, very low-temperature diffuse venting site Ula Nui, approximately the top $5-10 \mathrm{~cm}$ of layered $\mathrm{Fe}-\mathrm{Mn}$ microbial mats were collected in scoop-samplers and were stored fresh and frozen as fully (4) "intact" map samples. All of the mat samples examined for this study are reported in Table 1. The term "fresh" mat is applied to samples that were stored at $4^{\circ} \mathrm{C}$ and analyzed within 1 month of seafloor recovery. The term "aged" mat is applied to samples stored at $4^{\circ} \mathrm{C}$ and analyzed after 0.5 to greater than 1 year after seafloor recovery.

\section{X-RAY ABSORPTION SPECTROSCOPY Iron $K$-edge $X$-ray absorption microspectroscopy}

$\mathrm{X}$-ray microprobe measurements were performed for three types of Loihi mat samples: (a) intact surface crust from Ula Nui; (b) fresh mat flocs; and (c) $4^{\circ} \mathrm{C}$ aged mat flocs.

One intact surface crust of an Fe-Mn layered mat from Ula Nui was prepared for X-ray microprobe element mapping by slicing a $3-\mathrm{mm}$ thick by $8 \mathrm{~cm}$ wide by $4 \mathrm{~cm}$ tall section of a sample frozen at $-20^{\circ} \mathrm{C}$. The slice was then positioned into an anaerobic aluminum sample holder with thin mylar windows that was

Table 1 | Description of the Loihi Seamount vent areas and vent fluid properties.

\begin{tabular}{|c|c|c|c|c|c|c|c|c|c|c|c|c|}
\hline \multirow[t]{2}{*}{ Area } & \multirow[t]{2}{*}{ Description } & \multirow[t]{2}{*}{ Depth (m) } & \multicolumn{2}{|c|}{$T_{\max }\left({ }^{\circ} \mathrm{C}\right)^{\mathrm{a}}$} & \multicolumn{2}{|c|}{$\mathrm{pH}_{\max }$} & \multicolumn{2}{|c|}{$[\mathrm{Si}]_{\max }{ }^{b}$} & \multicolumn{2}{|c|}{$[P]_{\max }$} & \multicolumn{2}{|c|}{$[\mathrm{Fe}]_{\max }$} \\
\hline & & & 2006 & 2007 & 2006 & 2007 & 2006 & 2007 & 2006 & 2007 & 2006 & 2007 \\
\hline Ula Nui & Ultra-diffuse, cold, base of seamount & 4988 & 1.75 & 1.75 & & & - & - & - & - & $127^{\mathrm{c}}$ & - \\
\hline Naha & Extinct, rim of Pele's Pit & 1325 & \multicolumn{2}{|c|}{$<2.8$} & - & - & - & - & - & - & - & - \\
\hline Spillway & Active, warm, rim of Pele's Pit & 1272 & 54.0 & 55.0 & 6.37 & 6.72 & 4664 & 2599 & 9.1 & 3.1 & 726.7 & 354.7 \\
\hline Tower & Active, warm, Pele's Pit & 1304 & 51.0 & 50.0 & 6.01 & 6.29 & 2966 & 3092 & 6.2 & 4.8 & 557.8 & 407.1 \\
\hline Hiolo & Active, warm, Pele's Pit & 1302 & 51.0 & 52.0 & 5.94 & 6.69 & 3830 & 4131 & 6 & 6.1 & 568.8 & 577.8 \\
\hline Lohiau & $\begin{array}{l}\text { Active, cool, Pele's Pit site, frequently } \\
\text { sampled }\end{array}$ & 1174 & 22.0 & 24.5 & 6.21 & 6.94 & 1558 & 675 & 2.5 & 1.2 & 234.7 & 68.3 \\
\hline Hiolo Ridge & Active, warm, rim of Pele's Pit & 1116 & 14.6 & - & - & - & - & - & - & - & 224 & - \\
\hline Pohaku & $\begin{array}{l}\text { Active, warm, rim of Pele's pit, not } \\
\text { previously sampled }\end{array}$ & 1180 & - & 26.5 & - & 7.32 & - & 2210 & - & 4.5 & - & 796.4 \\
\hline
\end{tabular}

${ }^{a}$ Data from Glazer and Rouxel (2009).

${ }^{b} A / l$ concentrations in micro molar.

'Data from Edwards et al. (2011). 
continuously purged with helium at room temperature. Three different regions of the slice were then mapped - "R1," a 200$\mu \mathrm{m} \times 200-\mu \mathrm{m}$ region at the very top surface of the mat, "R2," a $1600-\mu \mathrm{m} \times 200-\mu \mathrm{m}$ region located $400 \mu \mathrm{m}$ below the surface of the mat, and then "R3," a final $200 \mu \mathrm{m} \times 200 \mu \mathrm{m}$ region in the middle of the mat. Each map area was sequentially raster scanned at three energies across the Mn K-edge $(6545,6550$, and $6560 \mathrm{eV}$ ) and then three energies across the Fe K-edge (7120, 7126, and $7133 \mathrm{eV}$ ) at BL 2-3 at the Stanford Synchrotron Radiation Lightsource using a Si $220 \mathrm{phi}=0$ monochromator detuned $30 \%$ and a focused spot size of $2 \mu \mathrm{m} \times 2 \mu \mathrm{m}$. Full X-ray fluorescence spectra were collected for each pixel with a $100-\mathrm{ms}$ dwell time using a three-element germanium detector. A matrix of predicted $\mathrm{Fe}(\mathrm{II})$ versus $\mathrm{Fe}(\mathrm{III})$ and $\mathrm{Mn}$ (II) versus $\mathrm{Mn}$ (IV) fluorescence yields at each incident energy was generated from the Fe X-ray absorption near-edge structure (XANES) spectra of a reduced basalt glass $[88 \% \mathrm{Fe}(\mathrm{II})]$ versus the $100 \% \mathrm{Fe}(\mathrm{III})$-oxide standard, and the Mn XANES spectra of $\mathrm{Mn}_{(\mathrm{aq})}^{2+}[100 \% \mathrm{Mn}(\mathrm{II})]$ and $\delta-\mathrm{MnO}_{2}[100 \% \mathrm{Mn}(\mathrm{IV})]$ standards (e.g., Templeton et al., 2009). The resulting $I_{0}$-normalized, dead time-corrected element distribution, and oxidation-reduction maps were generated using Microanalysis Toolkit (Webb, 2006). Iron and Mn K-edge XANES spectra were also collected from specific spots in each map and analyzed using SixPack to confirm the oxidation states of Fe and Mn by comparison to our model compound library.

$\mathrm{X}$-ray microprobe measurements were also conducted among a random assortment of disseminated mat particle aggregates (flocs) to determine Fe speciation. These fresh and aged Loihi mat flocs (Lohiau, Pohaku, Naha, and Ula Nui) were deposited on polycarbonate membranes $(0.2 \mu \mathrm{m}$ pore size $)$ and rinsed with purified water using a glass filtration tower (MilliPore) and hand vacuum pump. Mat samples were analyzed at room temperature on the membrane with no further processing using a published method (Toner et al., 2009). Briefly, microprobe Fe extended X-ray absorption fine structure (EXAFS) spectra were collected at the Advanced Light Source on beamline 10.3.2 with a seven-element germanium detector in fluorescence mode (Marcus et al., 2004). The monochromator energy calibration was set with Fe foil at $7110.75 \mathrm{eV}$. The spectra were collected to a reciprocal space $(k)$ value of 14.4 $\left(\AA^{-1}\right)$ whenever possible. Individual scans collected at the same sample location were examined for changes in line-shape and peak position, and no photon-induced sample damage was observed. Spectra were dead time-corrected, energy calibrated, and averaged using custom beamline software (Marcus et al., 2004) and converted to $k$-space using SixPack (Webb, 2005). No over-absorption corrections were applied to EXAFS data.

\section{Bulk iron K-edge X-ray absorption spectroscopy}

Bulk Fe EXAFS spectra were collected for two types of Loihi mats: (1) frozen samples stored and analyzed under inert gas; and (2) "dry" samples that were frozen shipboard, and defrosted, rinsed, dried, and analyzed in ambient atmosphere.

Synchrotron-based Fe K-edge EXAFS spectra for two bulk mat flocs (Spillway and Hiolo mats) were collected from 7000 to $8000 \mathrm{eV}$ on beamline 11-2 at the Stanford Synchrotron Radiation Lightsource using a $\mathrm{Si}(220)$ phi $=0$ monochromator crystal detuned $30 \%$ for harmonic rejection, and a Lytle detector for fluorescence measurements. All data reduction including averaging, dead time correction, and post-edge normalization was conducted using SixPack to generate background-subtracted, $k^{3}$ weighted EXAFS spectra. Spectra were calibrated using the first inflection of a $\mathrm{Fe}^{0}$ foil at $7112 \mathrm{eV}$. These three mat samples were analyzed in a hydrated state after being thawed and loaded into a $2-\mathrm{mm} \times 20-\mathrm{mm}$ slit in a 1-mm mylar holder sealed with kapton tape in an anaerobic chamber. The mylar sample holder was maintained under anaerobic conditions on BL 11-2 by continuously flushing nitrogen through a specialized sample box attached to the fluorescence detector.

Several dry Loihi mat samples (Ula Nui-A, Ula Nui-B, Lohiau A, Spillway A, and BT37) were applied to double-sided adhesive in thin layers. Mat samples were analyzed at room temperature with no further processing. Bulk Fe EXAFS were collected at the Advanced Photon Source on beamline 20-BM in transmission mode. The monochromator energy was set with $\mathrm{Fe}$ foil at $7110.75 \mathrm{eV}$. The spectra were collected to a reciprocal space $(k)$ value of greater than $15\left(\AA^{-1}\right)$. Individual scans were examined for changes in line-shape and peak position, and no photon-induced sample damage was observed. Spectra were dead time-corrected, energy calibrated, averaged, and converted to $k$-space using Athena (Ravel and Newville, 2005). The spectra were compared to reference Fe oxyhydroxides (goethite and two-line Fh) synthesized using published methods (Cornell and Schwertmann, 2003), and sample preparation and data collection were identical to that described for the dry Loihi mat samples.

Reference Fe EXAFS spectra for this data set include goethite, six-line Fh, two-line Fh, lepidocrocite, hematite, siderite, green rust sulfate, jarosite, marcasite, magnetite, vivianite, and $\mathrm{Fe}(\mathrm{III})$ phosphate (Hansel et al., 2003), as well as Fe-smectite (O'Day et al., 2004), additional Fe-silicates such as basalt, olivine, pyroxene, chlorite, Fe-bearing serpentine and talc group minerals (Mayhew et al., 2011), and a biogenic Fe oxyhydroxide formed during a seafloor sulfide incubation study (Toner et al., 2009).

\section{SYNCHROTRON RADIATION X-RAY DIFFRACTION AND TOTAL SCATTERING}

High-energy X-ray total scattering experiments were conducted at beamline 11-ID-B of the Advanced Photon Source, Argonne National Laboratory. Selected dry mat samples (Ula Nui-A/B, Lohiau A, Spillway A, and BT37) were packed into $\sim 1 \mathrm{~mm}$ O.D. polyimide (Kapton) capillaries and the scattered intensity from the samples was collected at ambient temperature with an amorphoussilicon-based flat-panel detector system (Perkin Elmer) mounted orthogonal to the incident beam path. For synchrotron radiation X-ray diffraction (XRD; SR-XRD) measurements the X-ray energy was fixed at $\sim 58 \mathrm{keV}(\lambda=0.2128 \AA)$ and the sample-todetector distance was optimized to cover $d$-spacings ranging from $\sim 0.5$ to $8.5 \AA$. For pair distribution function (PDF) experiments the X-ray energy was fixed at $\sim 90.5 \mathrm{keV}(\lambda=0.13702 \AA)$ and a sample-to-detector distance of $\sim 21.5 \mathrm{~cm}$ was chosen. This experimental geometry yielded scattering data with a maximum usable $Q$-range of $30 \AA^{-1}$ (where $Q=4 \pi \sin \theta \cdot \lambda^{-1}$ is the magnitude of the scattering vector or momentum transfer). The total exposure time for the blank (i.e., empty capillary) was $3200 \mathrm{~s}$ and each sample was 1200 s. Fit2D (Hammersley et al., 1996) was 
used to convert two-dimensional data to one-dimensional intensity versus scattering angle $(2 \theta)$. The experimental total scattering structure function $S(Q)$, reduced structure function $f(Q)$, and PDF were obtained using PDFgetX2 (Qiu et al., 2004). The data were corrected for parasitic background scattering and inelastic contributions (e.g., Compton scattering) as well as those corrections unique to image-plate geometry (Chupas et al., 2003). A Lorch modification function (Lorch, 1969) was applied.

The PDF, or $G(r)$, is the Fourier transform of the reduced structure function and has been described in detail elsewhere (Guinier, 1963; Egami and Billinge, 2003). In general, peaks in the PDF occur at characteristic distances separating pairs of atoms, and thus the $\mathrm{PDF}$ is an averaged representation of structure. As discussed below, additional information such as the scattering domain size can be extracted from the attenuation in peak intensities with increasing $r$ (see Gilbert, 2008 for review). In this study, the maximum coherent scattering domain (CSD) size for the samples and references is estimated from the PDFs and is reported with an error of $\pm 3 \AA$ (Hall et al., 2000). Structural information was extracted directly from the experimental PDFs by fitting the features with Gaussian functions (PeakFit v4.12). At shorter length scales $(<\sim 2.5 \AA)$ the peak positions yield actual average bond lengths (e.g., Si-O, $\mathrm{Fe}-\mathrm{O})$. At longer length scales the PDF becomes more complicated because peaks from different origins overlap. As such, the full width at half maximum (FWHM) of the Gaussian functions were varied together in order to minimize the number of free parameters. In addition, the positions of peaks at 3.03 and $3.44 \AA$ (representing edge- and corner-sharing Fe polyhedra, respectively, as described below) were fixed during fitting of the natural samples in order to further constrain the number of degrees of freedom. As discussed below, the presence of at least edge-sharing Fe polyhedra is further justified by the EXAFS results for these samples.

Synthetic two-line Fh and amorphous silica were used as references. Ferrihydrite was precipitated at room temperature by the rapid hydrolysis of $0.1 \mathrm{M} \mathrm{Fe}\left(\mathrm{NO}_{3}\right)_{3}$ to $\mathrm{pH} 7$ with $2 \mathrm{M} \mathrm{NaOH}$. Amorphous $\mathrm{SiO}_{2}\left(a m-\mathrm{SiO}_{2}\right)$ was precipitated by hydrolysis of tetraethyl orthosilicate $\left[\mathrm{Si}\left(\mathrm{OC}_{2} \mathrm{H}_{5}\right)_{4}\right.$ (Fisher Scientific)] with $12 \mathrm{M}$ $\mathrm{HCl}$ according to the procedure described by Hirata et al. (2003).

\section{MAGNETISM}

A commercial SQUID magnetometer (MPMS-XL-Quantum Design) was used to measure induced magnetization curves [zero field cooling (ZFC) and field cooling (FC)], hysteresis loops, room temperature saturation isothermal remanent magnetization (RTSIRM), and AC susceptibility as a function of temperature, and frequency (Institute for Rock Magnetism, University of Minnesota). ZFC induced magnetization curves were obtained by cooling the samples in zero field from 300 to $2 \mathrm{~K}$, then the magnetization was recorded as temperature increases in a small applied field $(B=5 \mathrm{mT})$. For field cooled induced magnetization curves, the sample is cooled to $2 \mathrm{~K}$ in a $5-\mathrm{mT}$ applied field, and magnetization is measured as temperature increases. Hysteresis loops were obtained by using maximum applied fields up to $5 \mathrm{~T}$ at temperatures from 2 to $300 \mathrm{~K}$. RTSIRM curves were obtained by applying a field of $2.5 \mathrm{~T}$ at room temperature, and measuring the remanent magnetization upon cooling to $10 \mathrm{~K}$, and then warming back to $300 \mathrm{~K}$. The AC susceptibility curves are measured for variable frequencies $(1-1000 \mathrm{~Hz})$ in the temperature range $2-300 \mathrm{~K}$.

To estimate the particle size using $\mathrm{ZFC}$ data, the $T_{\mathrm{P}}$ temperatures were identified directly from ZFC curves and the particle volume was obtained by the Néel-Arrhenius Law:

$\tau=\tau_{0} \mathrm{e}^{\frac{K V}{k_{\mathrm{BT}}}}$

where $T=T_{\mathrm{P}}, \tau$ is the measuring time, $\tau_{0}$ is a constant characteristic of the material $\left(10^{-9}-10^{-11} \mathrm{~s}\right), V$ is volume and $k_{\mathrm{B}}$ is Boltzmann's constant. After mathematical manipulation the above equation can be rewritten as

$V=\frac{25 k_{\mathrm{B}} T}{K}$

The volume was estimated considering particles with spherical geometry and Fh anisotropy constant of $K=1.7 \times 10^{5} \mathrm{~J} / \mathrm{m}^{3}$ (Rodmacq, 1984). The values of constant of anisotropy $K$ of Fh available in the literature are still under debate and could be a source of uncertainty in this estimate. The range of $K$ values reported in the literature include: $3.6 \times 10^{5} \mathrm{~J} / \mathrm{m}^{3}$ (Gilles et al., 2000); $3.12 \times 10^{5} \mathrm{~J} / \mathrm{m}^{3}$ (Duarte et al., 2006); $1.0 \times 10^{5} \mathrm{~J} / \mathrm{m}^{3}$ (Berquó et al., 2009); $4.7 \times 10^{5}-1.5 \times 10^{4} \mathrm{~J} / \mathrm{m}^{3}$ (Silva et al., 2008); $1.7 \times 10^{5} \mathrm{~J} / \mathrm{m}^{3}$ (Suzdalev et al., 1996). Another source of error is related to the fact that the model used to calculate particle size of natural Fh considered spherical particles. Previous work on synthetic Fh (Erbs et al., 2008) suggests that these particles may have an aspect ratio that is greater than 1 . As such, the estimates obtained here are considered upper limits and are useful to identify particle size changes associated with the vents temperature.

\section{MÖSSBAUER SPECTROSCOPY}

A conventional constant-acceleration spectrometer (Institute for Rock Magnetism, University of Minnesota) was used in transmission geometry with a ${ }^{57} \mathrm{Co} / \mathrm{Rh}$ source, using $\alpha$-Fe at room temperature to calibrate isomer shifts (ISs) and velocity scale. The magnetic hyperfine parameters such as magnetic hyperfine field $\left(B_{\mathrm{HF}}\right), \mathrm{IS}$, and quadrupole splitting (QS) were fitted using the NORMOS program (Brand, 1987).

\section{HEAT TREATMENT OF HIOLO MAT FLOCS}

The Hiolo mat was subjected to heating experiments in an oven to determine the temperature at which the Fh-like minerals transformed to hematite. One mat sample (Hiolo) was dried and divided in five aliquots. One part was kept without thermal treatment and the other four aliquots were used for thermal treatment at different temperatures. The heating procedure started and finished always with samples at room temperature reaching a maximum temperature $\left(T_{\max }\right)$ of $400,500,600$, or $800^{\circ} \mathrm{C}$. After the oven reached $T_{\max }$ the samples were maintained at that temperature for about $20 \mathrm{~min}$, and then samples were cooled inside the oven. Powder XRD measurements were conducted for mat samples using a PANalytical X-Pert PRO MPD X-ray diffractometer equipped with a cobalt source and high speed detector (X-Clerator; Laboratory of R. Lee Penn, Department of Chemistry, University of Minnesota). The data were collected over the range of $10-902 \theta^{\circ}$, with a scan rate 
of $0.6^{\circ} / \mathrm{min}$, and data are compared to reference powder diffraction patterns. Mössbauer spectra were also collected for the heat treated mat, as described in Section "Mössbauer Spectroscopy."

\section{ELEMENTAL ANALYSES}

Thawed Loihi Fe mat samples were prepared for elemental analysis (Aqueous Geochemistry Laboratory, Department of Earth Sciences, University of Minnesota) by $3 \times$ centrifugation and rinsing steps (18.2 $\Omega$ Milli-Q water), followed by drying for $24 \mathrm{~h}$ at $50^{\circ} \mathrm{C}$. The dried samples were dissolved in $6 \mathrm{~mL}$ of a $50 / 50$ mixture of Trace Grade $\mathrm{HCl}$ and $\mathrm{HNO}_{3}$, and diluted with $18.2 \Omega$ water to a total volume of $30 \mathrm{~mL}$. Major elements ( $\mathrm{Al}, \mathrm{B}, \mathrm{Ba}, \mathrm{Ca}, \mathrm{Co}, \mathrm{Cr}$, $\mathrm{Cu}, \mathrm{Fe}, \mathrm{K}, \mathrm{Li}, \mathrm{Mg}, \mathrm{Mn}, \mathrm{Na}, \mathrm{Ni}, \mathrm{P}, \mathrm{Si}, \mathrm{Sr}, \mathrm{Zn}$ ) were measured using a Thermo Scientific iCAP 6500 dual view Inductively Coupled Plasma-Optical Emission Spectrometer. The mat solutions were diluted for analysis with a cesium matrix modifier and yttrium as an internal standard. For trace metal analysis, the dissolved samples were diluted $40 \times$, and $40 \mathrm{ppb}$ of In internal standard was added. Trace elements (Be, Al, Sc, Ti, V, Ga, As, Se, Rb, Y, Zr, Mo, Ag, Cd, Cs, Ba, La, Ce, Pr, Nd, Sm, Eu, Gd, Tb, Dy, Ho, Er, Tm, Yb, $\mathrm{Lu}, \mathrm{Ta}, \mathrm{W}, \mathrm{Pb}, \mathrm{Th}$, and $\mathrm{U}$ ) were measured using a Thermo Scientific XSERIES 2 ICP-MS w/ESI PC3 Peltier cooled spray chamber, SCFAST injection loop, and SC-4 autosampler. All elements except $\mathrm{Li}, \mathrm{Be}, \mathrm{Al}$, were analyzed using $\mathrm{He} / \mathrm{H}_{2}$ collision-reaction mode.

To quantify organic carbon contents in several mats, 7-25 mg of material was leached in $0.1 \mathrm{~N} \mathrm{HCl}$, dried, reweighed, loaded into tin capsules, and analyzed using a Costech CHN 4010 elemental combustion system.

\section{RESULTS}

\section{IRON X-RAY ABSORPTION SPECTROSCOPY}

Microprobe Fe EXAFS spectra were collected for fresh and $4^{\circ} \mathrm{C}$ aged Loihi Fe microbial mats (Ula Nui, Lohiau, Naha, and Pohaku; slurp samples; Table 1). The microprobe EXAFS data are presented in Figure 1 along with bulk EXAFS data and selected reference spectra of Fe oxyhydroxides (goethite, two-line Fh, and Juan de Fuca Ridge biogenic Fe oxyhydroxide). Point measurements from different particle aggregates within the mat samples indicate that Fe speciation was homogeneous at a spatial scale of $10 \mu \mathrm{m}^{2}$. Comparison between the microprobe and bulk Fe EXAFS spectra for these mat flocs shows that the Fe speciation measured at the microscale is also representative of the bulk Fe speciation (Figure 1; Table 2).

Iron EXAFS spectra (Figure A1 in Appendix) for the Ula Nui mat were collected on samples with different storage (frozen under $\mathrm{N}_{2}$, frozen in ambient atmosphere, and aged in ambient seawater at $4^{\circ} \mathrm{C}$ ) and preparation (thawed under $\mathrm{N}_{2}$, thawed/rinsed in ambient atmosphere, and thawed/rinsed/dried at $40^{\circ} \mathrm{C}$ ) on three different instruments (SSRL 2-3, ALS 10.3.2, and APS 20-BM). These spectra are very similar despite different storage, handling, and instruments. Although there is a perceptible line-shape difference in the EXAFS spectrum for the $4^{\circ} \mathrm{C}$ aged sample (Ula Nui C) at $k=7.5 \AA^{-1}$, the biggest difference among these Ula Nui spectra is observed in the amplitude of fluorescence versus transmission mode measurements. We interpret the lower amplitude in the fluorescence mode data to be over-absorption effects as the Loihi mats are up to $45.6 \%$ by weight Fe (Table 2). These observations

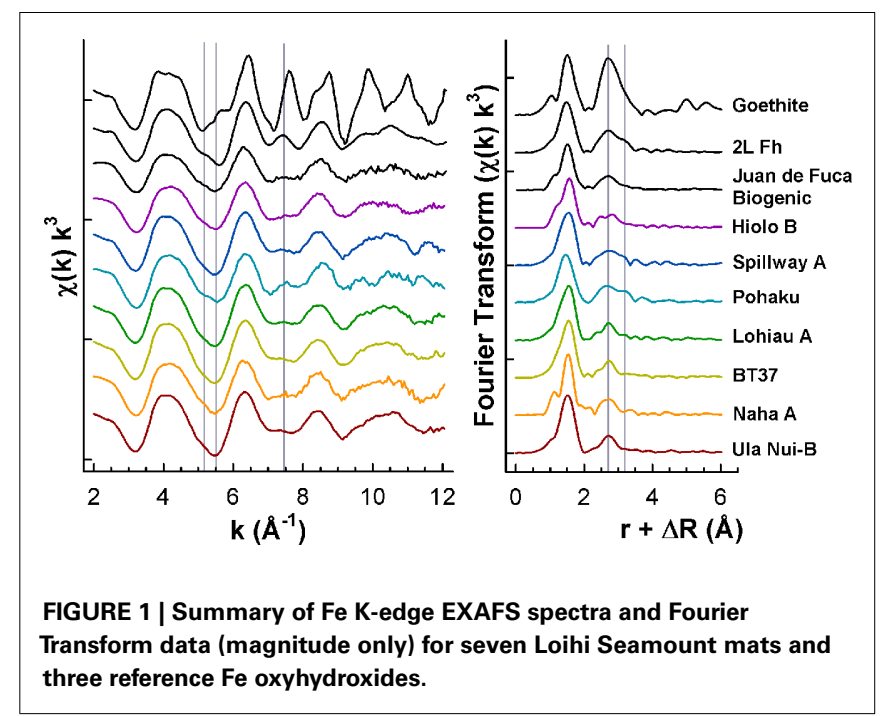

hold true for other mats examined by replicate EXAFS measurements. Therefore, in Figure 1 only representative EXAFS spectra from Loihi mats are displayed while a full summary of spectra are available in Figure A2 in Appendix.

In Figure 1, several spectral features are highlighted for the Loihi mats and reference minerals. The Fe EXAFS spectra collected for the Loihi mats have similarities with two-line Fh in terms of line-shape, amplitude, and phase. In the Fourier transformed data, a corresponding reduction or absence of the longer peak $(R+\Delta R=3.2 \AA)$ in the second Fe-Fe shell is observed (except for Pohaku; Figure 1). For the Fe oxyhydroxide goethite, the spectral feature observed in $k$-range $=7-8 \AA^{-1}$ corresponds to cornersharing $\mathrm{Fe}-\mathrm{O}$ octahedra and the three-dimensional character of the structure (Toner et al., 2009). The EXAFS data indicate that the mats are composed primarily of $\mathrm{Fe}$ (III) oxyhydroxide phases with less three-dimensional ordering than two-line Fh. Therefore, these $\mathrm{Fe}(\mathrm{III})$ phases will be referred to as natural short-range ordered Fh $\left(\right.$ Fh $\left._{\text {SRO }}\right)$ hereafter.

Iron and Mn oxidation state maps, coupled with total Fe, Mn, $\mathrm{Ca}$, and $\mathrm{Ti}$ distributions, were collected for an intact surface crust sample from the Ula Nui site (Figure 2). This sample was frozen shipboard under $\mathrm{N}_{2}$ and analyzed at the synchrotron in the absence of $\mathrm{O}_{2}$. Noticeable, discontinuous black banding can be observed visually in the laminated mats and these bands are represented in the X-ray fluorescence maps as regions of higher Mn fluorescence intensity [e.g., top of Region I (R1) and II (R2) in Figure 2]. XANES fitting of multiple energy maps collected across the Mn Kedge also indicates that these $\mathrm{Mn}$-rich regions are $\mathrm{Mn}$ (IV)-oxides. The valence state is confirmed by analysis of Mn K-edge XANES spectra for this sample (data not shown). The majority of the mat profile is then dominated by $\mathrm{Fe}$ (III) particles, although a zone dominated by reduced Fe(II) was mapped at the top of R2. Calcium is also enriched by more than an order of magnitude at the top of R2, and these Ca-rich zones envelop the particles in which Fe(II) is present. No micro-EXAFS spectra were collected on this sample and therefore the full speciation of the Fe in discrete regions is unknown, but possible candidate solid-phase Fe species include carbonates, sulfides, or basalt. The Fe(II)-rich particles are 
Table 2 | Summary of Loihi Seamount Fe mats examined. Solid-phase\% Fe, and Si:Fe and P:Fe mole ratios reported with sample handling and analyses information.

\begin{tabular}{|c|c|c|c|c|c|c|c|c|c|c|}
\hline \multirow[t]{2}{*}{ Year } & \multirow{2}{*}{$\begin{array}{l}\text { JASON2 } \\
\text { dive\# }\end{array}$} & \multirow{2}{*}{$\begin{array}{l}\text { Marker/ } \\
\text { sample } \\
\text { type }^{\text {a }}\end{array}$} & \multirow[t]{2}{*}{ Areab $^{b}$} & \multirow{2}{*}{$\begin{array}{l}\text { Mat } \\
\text { surface }\left({ }^{\circ} \mathrm{C}\right)\end{array}$} & \multirow[t]{2}{*}{$\%$ Fe (wt.) } & \multirow[t]{2}{*}{ Si:Fe } & \multirow[t]{2}{*}{ P:Fe } & \multicolumn{3}{|c|}{ Sample handling and analysis ${ }^{d}$} \\
\hline & & & & & & & & $\begin{array}{l}\text { Aged at } 4^{\circ} \mathrm{C} \\
\text { for microprobe } \\
\text { Fe EXAFS } \\
\text { (months) }\end{array}$ & $\begin{array}{l}\text { Frozen/ } \\
\text { rinsed/ } \\
\text { dried }^{c}\end{array}$ & $\begin{array}{l}\text { Frozen/ } \\
\text { no oxygen }\end{array}$ \\
\hline \multirow[t]{8}{*}{2006} & J2-241 & $2-5 / a$ & Lohiau C & - & - & - & - & - & A & - \\
\hline & J2-241 & $36 / a$ & Tower & 24.9 & - & - & - & - & A & - \\
\hline & J2-242 & $39 / a$ & Hiolo A & 51.0 & 45.6 & 0.145 & 0.041 & - & A & - \\
\hline & J2-242 & BT37/a & Hiolo Ridge & 11.0 & 39.8 & 0.245 & 0.028 & - & $A, B, C$ & - \\
\hline & J2-244 & a & Ula Nui-A & - & 29.9 & 0.289 & 0.168 & - & $A, B, C$ & - \\
\hline & J2-244 & a & Ula Nui-B; C & - & 30.7 & 0.227 & 0.138 & 5 & $A, B, C$ & - \\
\hline & $\mathrm{J} 2-245$ & $2-5 / a$ & Lohiau A & - & 41.0 & 0.207 & 0.035 & - & $A, B, C$ & - \\
\hline & J2-245 & $34 / a$ & Spillway A & 52.0 & 40.2 & 0.107 & 0.046 & - & $A, B, C$ & - \\
\hline \multirow[t]{6}{*}{2007} & J2-308 & $34 / b$ & Spillway B & $53.0-50.0$ & - & - & - & - & - & $\mathrm{B}$ \\
\hline & J2-308 & $39 / c$ & Hiolo B & 52.0 & - & - & - & - & - & $\mathrm{B}$ \\
\hline & J2-309 & $b, c$ & Ula Nui Crust & - & - & - & - & - & - & $D$ \\
\hline & J2-310 & $55 / a$ & Lohiau B & 5.5 & - & - & - & $<1 ; 13$ & - & - \\
\hline & $\mathrm{J} 2-315$ & $6 / a$ & Naha A; Naha B & - & - & - & - & $<1 ; 13$ & - & - \\
\hline & $\mathrm{J} 2-316$ & $57 / a$ & Pohaku & $17.3-20.0$ & - & - & - & 13 & - & - \\
\hline
\end{tabular}

aSeafloor sampling type: (a) slurp suction, (b) PVC scoop 1t, (c) PVC scoop $1 \mathrm{~b}$.

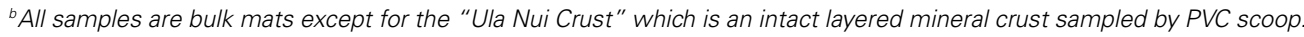

'Splits from slurp suction sampler made shipboard. One set was used for magnetism and Mossbauer, and the second set used for XAS and X-ray scattering.

${ }^{d}$ Measurements: $A=$ low-temperature magnetism and Mossbauer spectroscopy; $B=$ bulk Fe EXAFS; $C=X$-ray scattering; $D=$ microprobe Fe EXAFS.

likely not basalt given the lack of direct correlation to enrichments in $\mathrm{Mn}(\mathrm{II})$ or Ti expected in basaltic glass; there is also no Si as expected for phenocrysts of olivine or feldspar. Instead, carbonates may be forming due to the strong accumulation of $\mathrm{Fe}(\mathrm{II})$ and $\mathrm{Ca}$.

\section{SYNCHROTRON X-RAY DIFFRACTION AND PAIR DISTRIBUTION FUNCTION ANALYSIS}

Five Loihi mat samples (BT37, Ula Nui-A, Ula Nui-B, Spillway A, and Lohiau A) from the 2006 cruise were analyzed by SR-XRD, and all contain a Fh-like phase based on the presence of diffuse scattering features similar to those observed for the synthetic Fh reference (Figure 3). With exception of sample Ula Nui-B, the most significant features occur at $d$-spacings of $\sim 1.5$ and $\sim 2.55 \AA$ and are indicative of Fh (e.g., Jambor and Dutrizac, 1998; Michel et al., 2007a). The specific crystalline phases attributable to the sharper peaks evident in samples Ula Nui-A, Spillway A, and Lohiau A (Figure 3) could not be positively identified due to uncertainty in the relative intensities and possibility of multiple phases. Sample Ula Nui-A contains an additional mineral phase with peaks at $d$-spacings $\sim 7.2,3.5,2.5,1.4$, and $1.2 \AA$, that can be indexed as Na-rich birnessite (e.g., ICSD 68916). The presence of birnessite in the Ula Nui mat is consistent with Mn EXAFS data for the Ula Nui site (Edwards et al., 2011). Consistent with the SR-XRD results, the total scattering data collected to higher $Q$-space values and presented as the reduced structure functions for these samples (Figure 4) are also dominated by features similar to those observed for the synthetic Fh reference.
The Fourier transform of these reduced structure functions results in the PDFs, which contain structural information in realspace for the Loihi mat $\mathrm{Fh}_{\mathrm{SRO}}$ (Figure 5). The first two major features in the PDFs for the BT37, Ula Nui-A, Ula Nui-B, Spillway $A$, and Lohiau A mats correspond primarily to the average bond lengths for $\mathrm{Si}$ and $\mathrm{Fe}$ with oxygen. The peaks at $\sim 1.61 \AA$ correspond to Si-O correlations in the first oxygen shell of $\mathrm{Si}$ in tetrahedral coordination. This bond length agrees well with that reported in the literature (e.g., Grimley et al., 1990; Poulsen et al., 1995 ) and for the $a m-\mathrm{SiO}_{2}$ reference compound (Table 3). The second major peaks at $\sim 1.98 \AA$ correspond to $\mathrm{Fe}-\mathrm{O}$ correlations in the first oxygen shell of Fe. Iron(III) in synthetic Fh is dominantly in octahedral coordination with oxygen $(\mathrm{O}$ and/or $\mathrm{OH})$ although recent studies (Michel et al., 2007b, 2010; Maillot et al., 2011; Mikutta, 2011) support the presence of a minor amount (10-25\%) of tetrahedrally coordinated Fe(III). As such, the Fe-O correlation for the natural samples may have bond length contributions from both types of coordination environments. The Fe-O peak is slightly asymmetric and also has a small shoulder peak centered at $\sim 2.13 \AA$. Similar Fe-O bond lengths were reported for synthetic Fh (Maillot et al., 2011) based on EXAFS spectroscopy data. The fitted $\mathrm{Fe}-\mathrm{O}$ distances for the Loihi mat samples also correspond well with the Fh reference (Table 3), although the distances for the reference were slightly shorter at $\sim 1.96$ and $2.11 \AA$, respectively. Note that although the $\mathrm{Fe}-\mathrm{O}$ correlation, particularly in the case of the reference $\mathrm{Fh}$, is expected to have contributions from tetrahedrally coordinated Fe (average bond length $\sim 1.88 \AA$ ) only two Gaussian functions were used to avoid over fitting. 

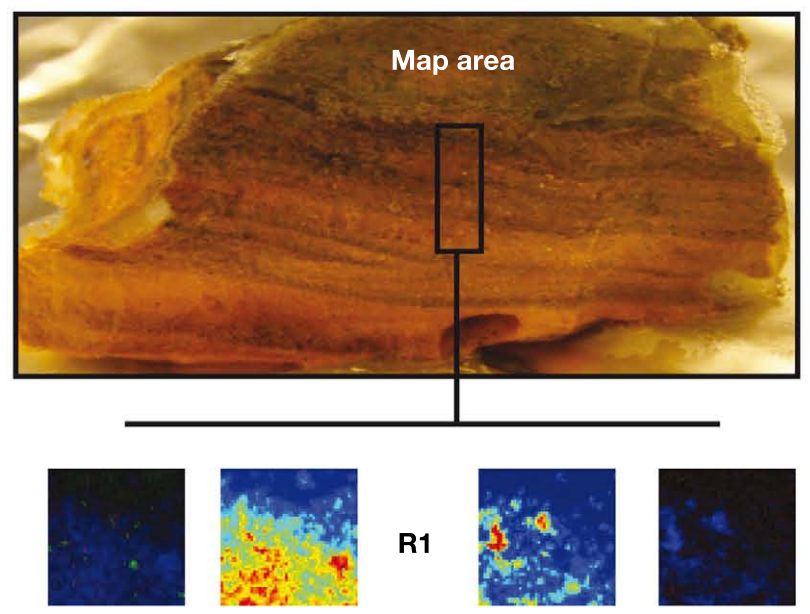

R1
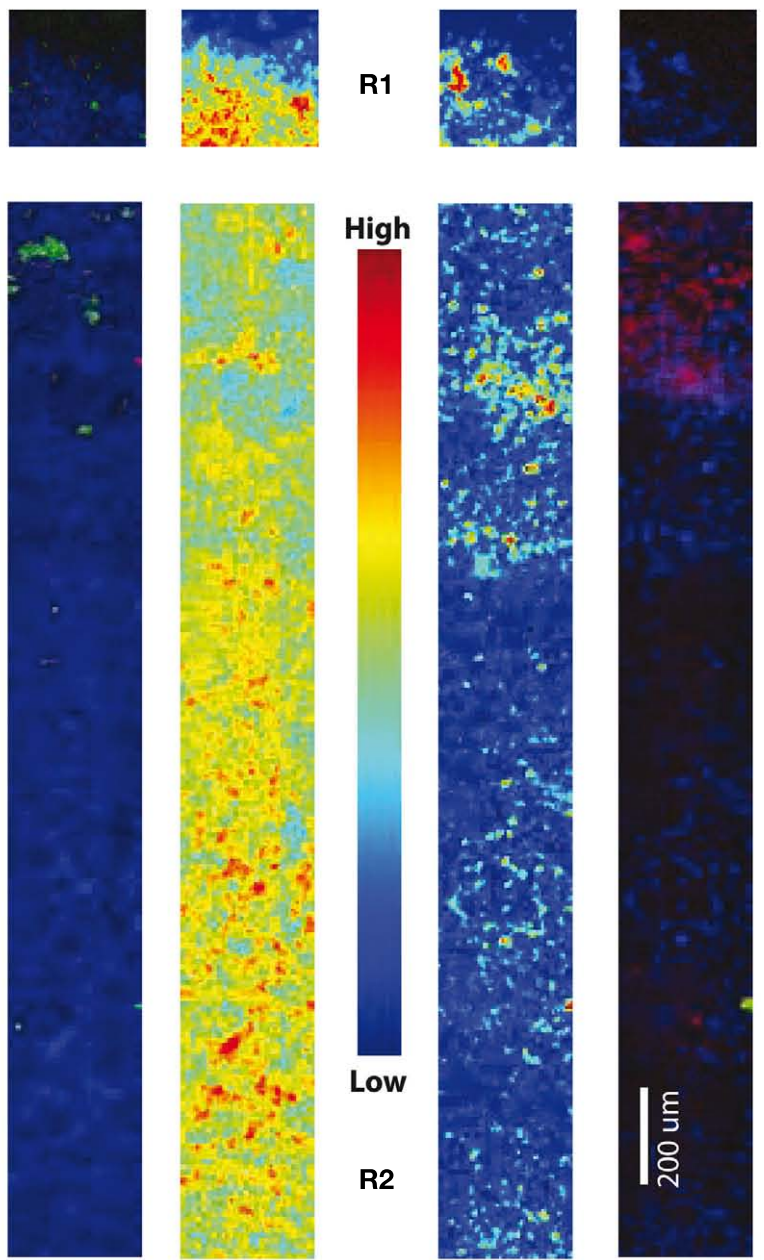

High
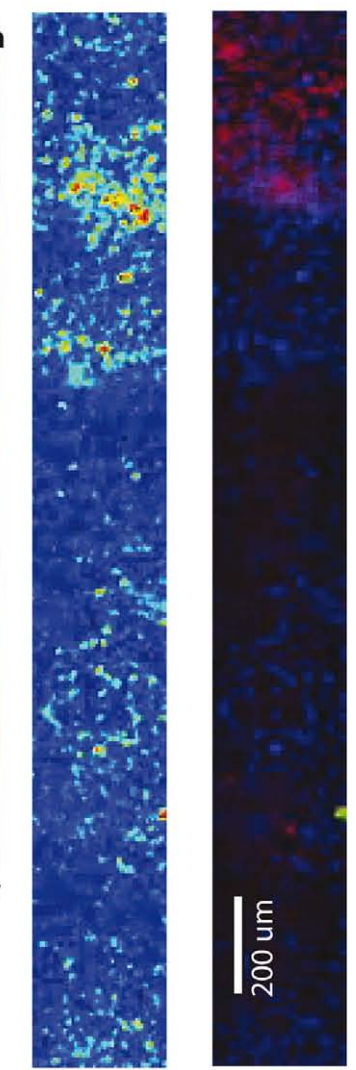

Oxidation State Map

$\mathrm{Ti}=$

$$
\mathrm{Fe}(\mathrm{III})=
$$$$
\mathrm{Fe}(\mathrm{II})=
$$

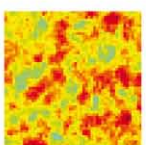

R3

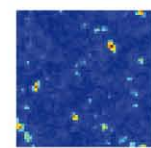

Oxidation State Map

Calcium =

$\mathrm{Mn}(\mathrm{IV})=$

$\mathrm{Mn}(\mathrm{II})=$

$$
\mathrm{Fe}_{\text {total }} \text { map } \quad \mathrm{Mn}_{\text {total }} \text { map }
$$

FIGURE 2 | X-ray microprobe fluorescence mapping of an intact Fe/Mn iron microbial mat from Ula Nui. Center maps for Regions 1 2 , and 3 (R1, R2, R3) show total Fe and Mn distributions, while outer maps are tricolor maps that include the redox distribution for

$\mathrm{Fe}(\mathrm{II}) / \mathrm{Fe}(\mathrm{III})$, and total Ti (left), as well as $\mathrm{Mn}(\mathrm{II}) / \mathrm{Mn}(\mathrm{IV})$, showing total $\mathrm{Ca}$ (right).
Subsequent features in the PDFs correspond to second, third, and higher neighbors around $\mathrm{Si}$ and $\mathrm{Fe}$, as well as oxygen pair correlations (i.e., O...O). For example, the small features at $\sim 2.64 \AA$ (Figure 5) are due to the O...O distance in tetrahedral 


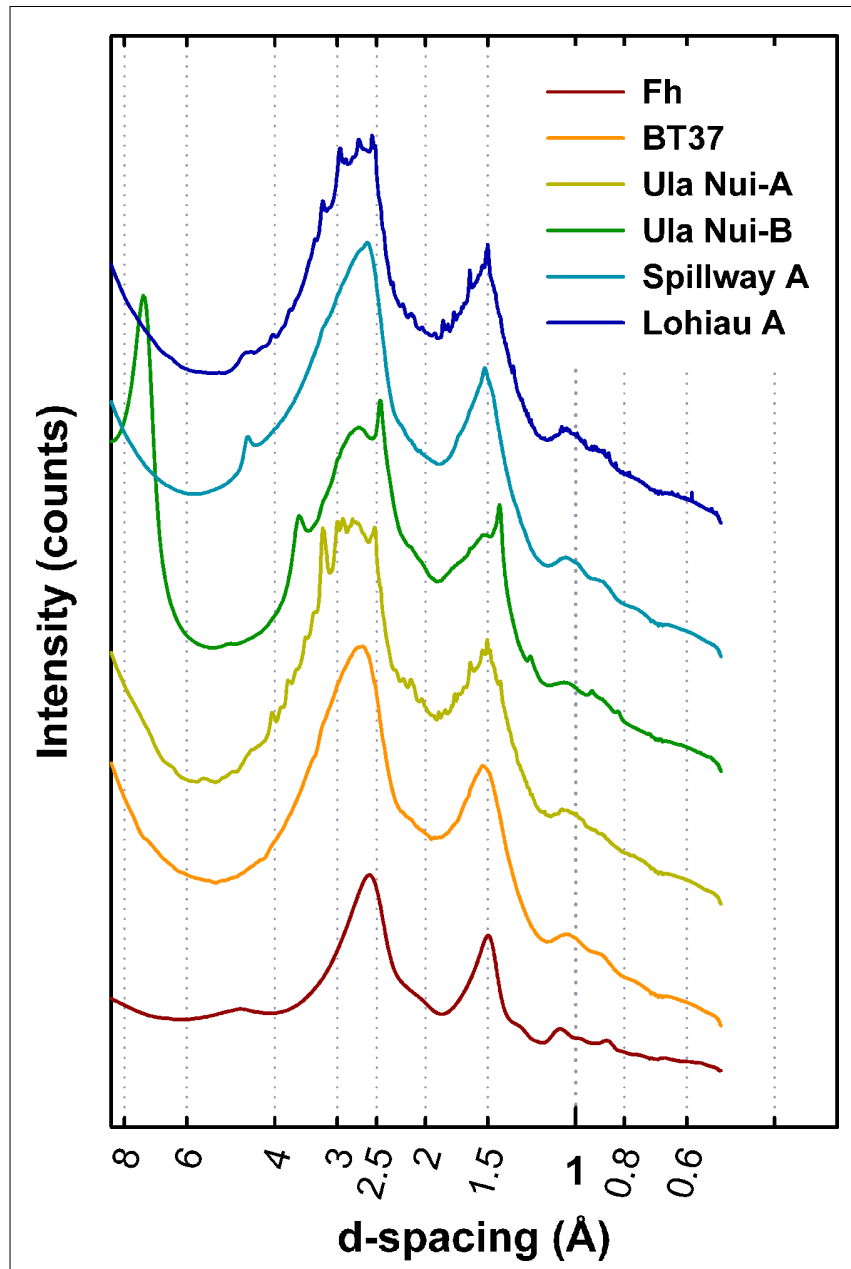

FIGURE 3 | Comparison of the synchrotron radiation X-ray diffraction plotted as $\boldsymbol{d}$-spacing versus intensity. Two broad features characteristic of two-line ferrihydrite (Fh, bottom) occur in all samples at $\sim 1.5$ and $2.55 \AA$. The most significant impurity phase appears in Ula Nui-B and can be indexed as birnessite, a layered $\mathrm{Mn}^{3+/ 4+}$ (hydr)oxide. Sharp peaks indicating the presence of trace impurities suspected as alumino-silicate phases are also observed in Ula Nui-A, Spillway A, and Lohiau A but could not be positively identified. Increasing background intensity at $d$-spacings greater than $\sim 6 \AA$ due to effects of small angle scattering.

silicate (Figure 6) and are consistent with data for the $\mathrm{am}-\mathrm{SiO}_{2}$ reference. Also based on the PDF for the reference, a Si. . .Si distance corresponding to corner-sharing silica tetrahedra is expected at $\sim 3.07 \AA$ (Figure 6) but is possibly obscured in the natural samples due, in part, to overlapping correlations resulting from the connectivity of $\mathrm{FeO}_{4 / 6}$ polyhedra. The peak at $\sim 3.03 \AA$ in synthetic $\mathrm{Fh}$ is dominated by Fe...Fe and $\mathrm{O}$... O correlations for edge-sharing Fe octahedra and the next major peak at $\sim 3.44 \AA$ has contributions from corner-sharing $\mathrm{FeO}_{4 / 6}$ polyhedra (Michel et al., 2010). These edge- and corner-sharing Fe contributions are not clearly resolved in the mat samples due to the presence of additional features (Figure 5) the most significant of which occur at 3.14, 3.31, and $3.6 \AA$ (Table 3). Previous work (Pokrovski et al., 2003) showed that in varying concentrations of $\mathrm{Si}$ solutions, the presence of one to two Si atoms was detected at $3.18 \pm 0.03 \AA$ in the second shell

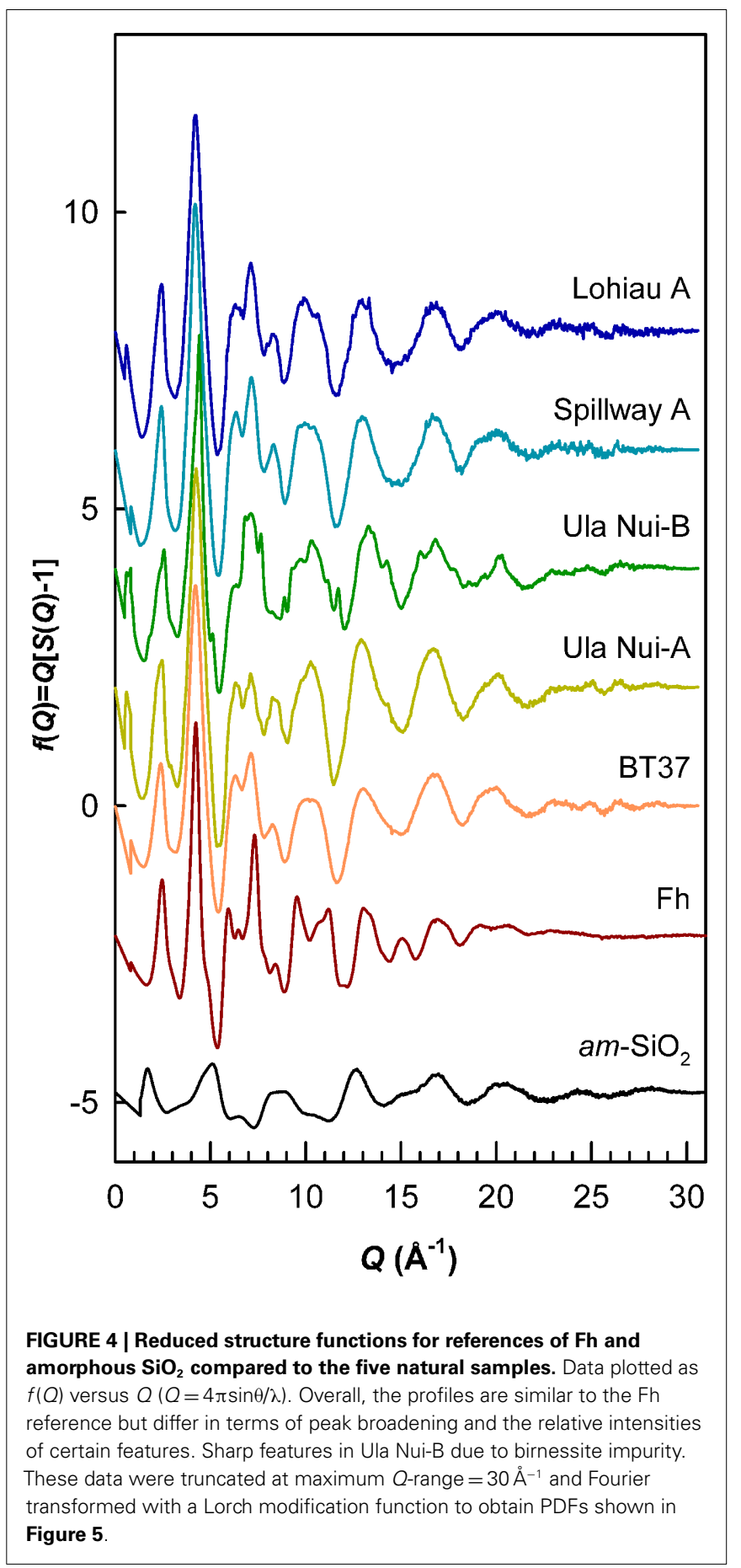

around $\mathrm{Fe}$ and was ascribed to $\mathrm{SiO}_{4}$ linked bidentate to two neighboring Fe octahedra via corners (Figure 6). Other bonding motifs are also possible (Figure 6) and longer Si...Fe path lengths could explain the features at distances of $\sim 3.3$ and $\sim 3.6 \AA$.

With exception of the degree of PDF decay, the most significant differences between the Loihi mat $\mathrm{Fh}_{\mathrm{SRO}}$ and Fh reference are in the range $2.5<r<4 \AA$. As described above, differences in this region of the PDFs appear primarily due to Si...Fe pair correlations. Interestingly, the pair correlations beyond $r \approx 4 \AA$ in BT37, 


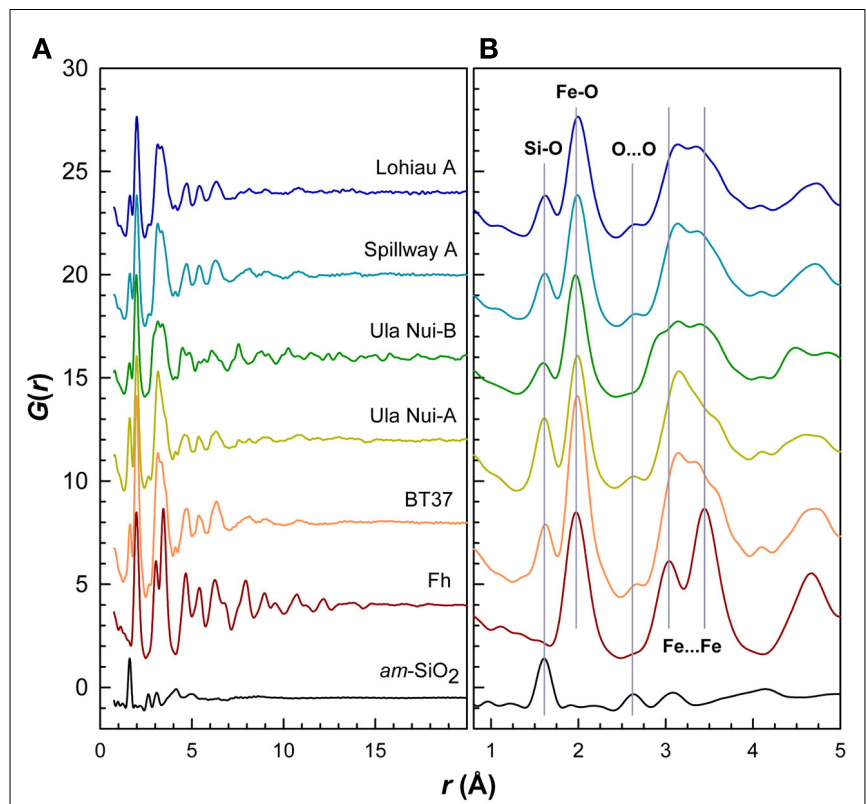

FIGURE 5 | Real-space PDFs or $\boldsymbol{G}(\boldsymbol{r})$ for the five natural samples compared to experimental PDFs for Fh and amorphous $\mathrm{SiO}_{2}$ references. (A) The strong attenuation in the features of the PDFs with increasing $r$ for the natural samples indicates smaller coherent scattering domain (CSD) sizes and increased disorder relative to synthetic Fh. Sample Ula Nui-B shows more structure at higher $r$ due to birnessite phase impurity. (B) Comparison of the short-range order for these samples. Similarities between natural samples and synthetic references for Fh and amorphous silica are highlighted.

Ula Nui-A, Spillway A, and Lohiau A closely resemble synthetic Fh (Figure A3 in Appendix) suggesting that the intermediate-range order and connectivity of Fe polyhedra are maintained over these length scales. The PDF peaks decay at $r \approx 16 \AA$ for BT37, Spillway A, and Lohiau A suggesting that these mat samples are more disordered and have smaller CSD sizes compared with synthetic two-line Fh which decays at $r \approx 23 \AA$ (Figure A3 in Appendix). Estimated CSD sizes for Ula Nui-A and Ula Nui-B (Table 3 ) are significantly larger ( $\sim 23$ and $37 \AA$, respectively) however, the presence of relatively crystalline impurities in these samples prevents an accurate estimate for the Fh fractions, which are assumed to be less crystalline than the associated impurity phases. Shifts in peak positions for the natural samples relative to Fh at higher $r(>4 \AA)$ may be attributable, in part, to increasing strain with decreasing CSD size, and this trend is consistent with previous studies of synthetic Fh in which the size and/or Fe(III) vacancy content varied (Michel et al., 2007a).

\section{LOW-TEMPERATURE MAGNETISM}

Representative ZFC/FC curves obtained for Loihi seamount samples are shown in Figure 7 and Table 4 summarizes the peak temperature estimated for different samples. Particle size estimates obtained from ZFC curves are also displayed in Table 4. A description of the Néel-Arrhenius Law, as well as a discussion of the assumptions used is included in the Section "Magnetism."

Typical hysteresis loops (Figure 7), for Loihi Seamount samples, obtained down to $2 \mathrm{~K}$ show blocked particles and the presence of coercive force $\left(H_{\mathrm{C}}\right)$ and remanent magnetization $\left(M_{\mathrm{R}}\right)$. Above $T_{\mathrm{P}}$ value, the hysteresis loops display only the behavior expected for unblocked particles, the loops are closed, and $H_{\mathrm{C}}$ and $M_{\mathrm{R}}$ are zero. For some samples the hysteresis loops are open above $T_{\mathrm{P}}$ as a result of the contribution of trace Ti-magnetite impurity (see also Figure A4 in Appendix). The particle diameters calculated by this method range from 3.5 to $4.5 \mathrm{~nm}$ for the Loihi Seamount natural Fh ${ }_{\text {SRO }}$ minerals.

\section{MÖSSBAUER SPECTROSCOPY}

Mössbauer spectra were obtained at room temperature and $4.2 \mathrm{~K}$ for selected Fe mat samples in order to confirm the valence state of Fe and the magnetic state of the FhSRO. Detailed chemical, structural, and magnetic information can be obtained with this method (Murad and Cashion, 2004), as the spectra depend on the mineralogy, lattice type, abundance of structural defects, and magnetic properties of the sample. The type of magnetic ordering (ferro, ferri-, or antiferromagnetic) can be further tested by applying external magnetic fields, and effects related to thermal relaxation in nanoparticles (superparamagnetism) are investigated by obtaining spectra at different temperatures.

The room temperature spectra for the Fe mat samples from the Spillway A, Tower, Hiolo A, Ula Nui-A, Ula Nui-B/C, Lohiau A, and BT37 areas of Loihi Seamount have a $\mathrm{Fe}^{3+}$ doublet and magnetic hyperfine parameters corresponding to Fh (Table 5; Figure 8). The presence of a doublet in a Mössbauer spectrum is a feature associated with paramagnetism and/or superparamagnetism. A superparamagnetic phase has magnetic order below the blocking temperature. The Mössbauer spectra of Fe mats taken at $4.2 \mathrm{~K}$ have magnetic order and they exhibit a sextet. The magnetic hyperfine parameters of Loihi mat samples at $4.2 \mathrm{~K}$ agree with the ones found in the literature for Fh (Berquó et al., 2009). A decrease was observed in the magnetic hyperfine field $\left(B_{\mathrm{HF}}\right)$ as compared with synthetic Fh; this feature is associated with structural defects. Ferrihydrite, specifically two-line Fh, has significant defects in both the tetrahedral and octahedral Fe(III) sites (Michel et al., 2010), and these natural Fh $\mathrm{SRO}_{\mathrm{S}}$ samples from Loihi Seamount seem to have extra Fe(III)-site lattice defects due perhaps to Fe substitution and vacancies.

\section{HEAT TREATMENT OF THE HIOLO MAT}

A Loihi Seamount mat from the Hiolo area was thermally treated to determine the temperature at which the natural Fh $\mathrm{SRO}_{\mathrm{S} O}$ converts to hematite under oxic conditions. The temperature dependent conversion was monitored by powder XRD and room temperature Mössbauer spectroscopy. The XRD pattern obtained for the unheated Hiolo mat sample is presented in Figure 9. The pattern has the two broad lines characteristic of $\mathrm{Fh}$ and is in agreement with the SR-XRD data for Ula Nui-A, Ula Nui-B/C, BT37, Spillway A, and Lohiau A (Figure 3). In addition to the Fh pattern, several sharp diffraction lines are evident for the sample under different conditions: (1) no thermal treatment, halite, and Fh; (2) sample treated at $400^{\circ} \mathrm{C}$, halite, Fh, and minor contribution of anhydrite $\left(\mathrm{CaSO}_{4}\right)$; (3) sample treated at $600^{\circ} \mathrm{C}$, halite, hematite $\left(\alpha-\mathrm{Fe}_{2} \mathrm{O}_{3}\right)$, and minor contribution of aegirine $\left(\mathrm{NaFeSi}_{2} \mathrm{O}_{6}\right)$; and (4) sample treated at $800^{\circ} \mathrm{C}$, halite, hematite, and minor contribution aegirine. The samples heated at 600 and $800^{\circ} \mathrm{C}$ have dominant, sharp diffraction lines consistent with the mineral hematite. 
Table 3 | Atom pair separations and coherent scattering domain sizes extracted from PDF analysis of references and selected mat samples.

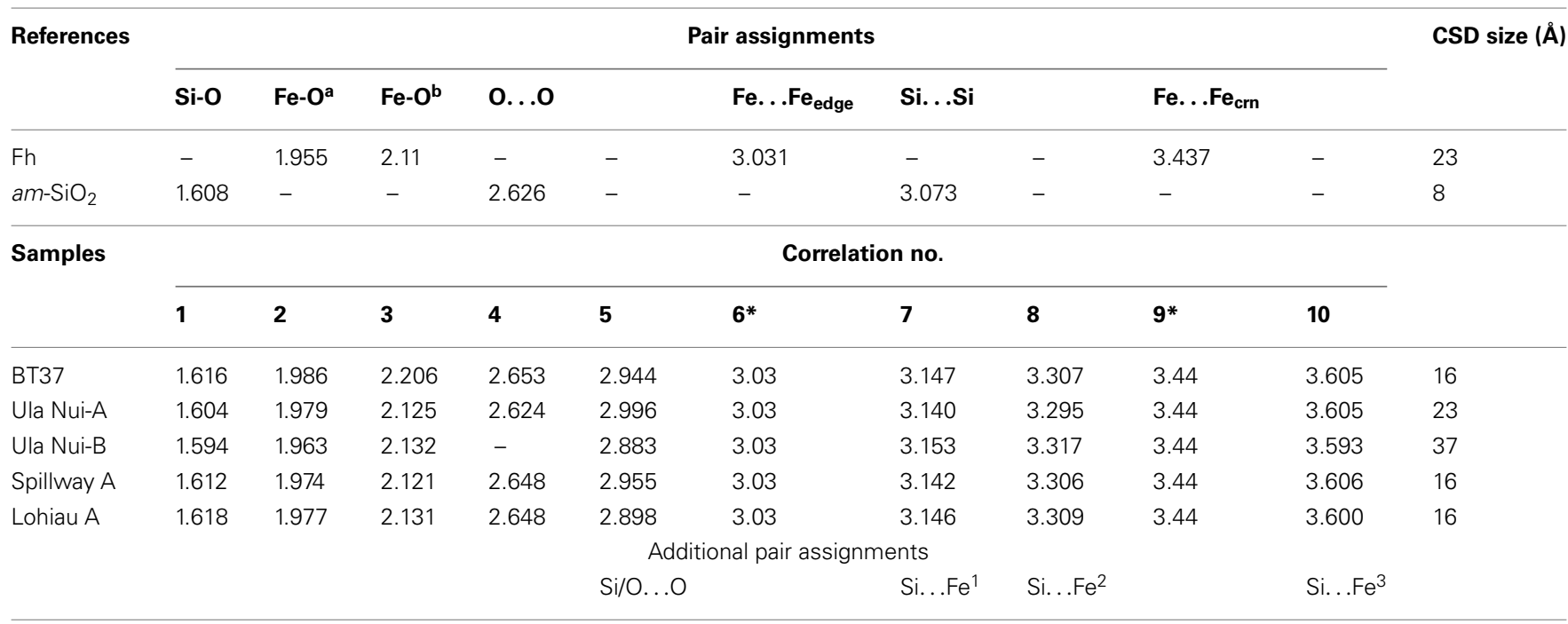

a,bTwo Gaussian functions were used to fit the correlation at $\sim 2 \AA$.

${ }^{1} \mathrm{SiO}_{4}$ linked bidentate to two neighboring Fe octahedra via corners.

$(-)$ indicates feature is not applicable (references only) or not present (samples only).

${ }^{2} \mathrm{SiO}_{4}$ linked monodentate to $\mathrm{O}$ doubly/triply coordinated with $\mathrm{Fe}$.

${ }^{*}$ Peak position fixed.

${ }^{3} \mathrm{SiO}_{4}$ linked monodentate to $\mathrm{O}$ singly coordinated with $\mathrm{Fe}$ (linear $\mathrm{Si}-\mathrm{O}-\mathrm{Fe}$ ).

Average error of $\pm 0.005 \AA$ in fitted peak position.

Estimated error of $\pm 3 \AA$ on $C S D$ size from Hall et al. (2000).

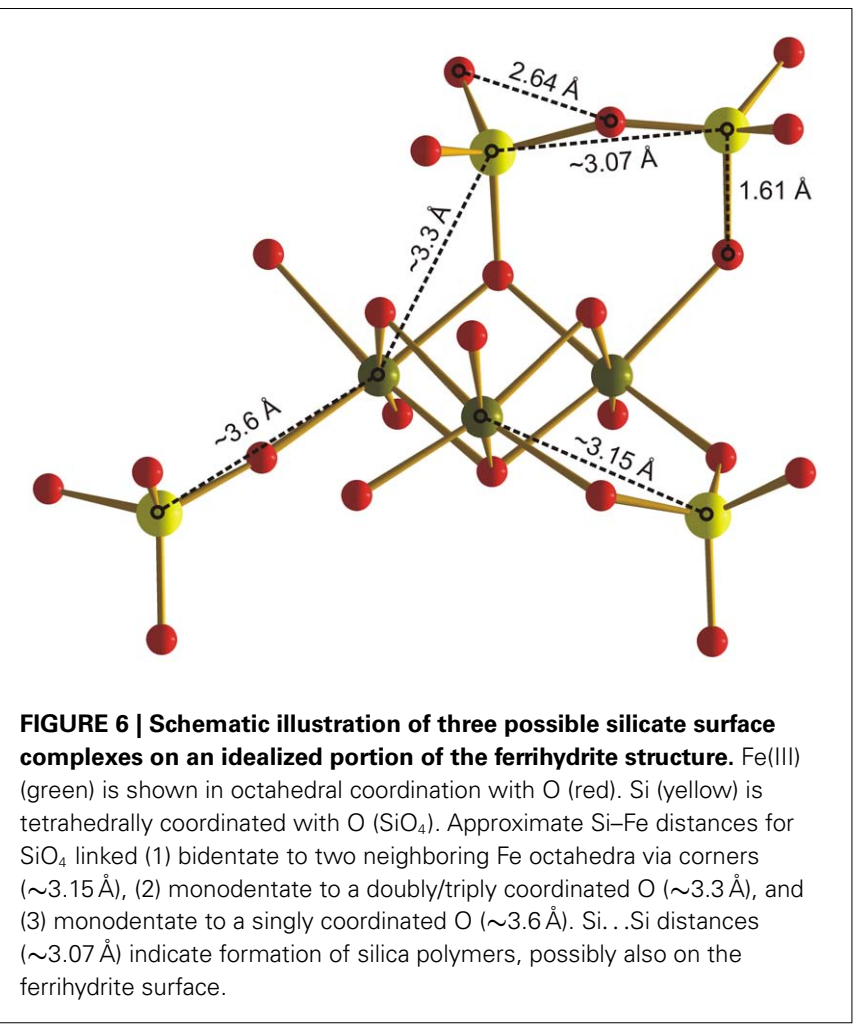

Mössbauer spectra tell a more detailed story of the mineral conversion (Figure 10). The Mössbauer spectra for the Hiolo mat, unheated, and after $400^{\circ} \mathrm{C}$ treatment, exhibit a doublet indicating a superparamagnetic phase. The Hiolo mat samples heated to $500^{\circ} \mathrm{C}$ showed the presence of at least two components, a sextet representing magnetic order at room temperature and a $\mathrm{Fe}^{3+}$ doublet. The doublet represents the contribution of Fh that was not converted to a more stable phase, while the sextet does not have parameters that correspond to a specific Fe phase. The Fe phase(s) observed at $500^{\circ} \mathrm{C}$ are intermediates in the conversion process from natural Fh $\mathrm{SRO}_{\mathrm{SR}}$ to hematite. In contrast, the spectra at 600 and $800^{\circ} \mathrm{C}$ suggest the presence of hematite. At $600^{\circ} \mathrm{C}$ the $B_{\mathrm{HF}}$ is reduced as compared with a stoichiometric hematite, indicating the presence of lattice defects in the conversion product. The data at $800^{\circ} \mathrm{C}$ show magnetic hyperfine parameters similar to stoichiometric hematite and suggest the thermal treatment completely converted $\mathrm{Fh}_{\mathrm{SRO}}$ to hematite at that temperature.

\section{DISCUSSION}

\section{MAT COMPOSITION AND STRUCTURE OF IRON-BEARING PHASES}

$\mathrm{X}$-ray fluorescence mapping of major element distributions with depth show that spatial heterogeneity and geochemical zonation occur in layered mats such as at the Ula Nui site. The low-temperature $\left(<2^{\circ} \mathrm{C}\right) \mathrm{Fe}$ mats at Ula Nui are considered to be modern analogs to ancient umber deposits that form from $\mathrm{Fe}$ and Si-rich ultra-diffuse hydrothermal fluids (Edwards et al., 2011). Total cell densities reach values as high as $1.4 \times 10^{9} \mathrm{cells} / \mathrm{g}$ dry wt. in the $\mathrm{Fe} / \mathrm{Mn}$ mats, and known Fe-oxidizing bacteria (e.g., Zeta-proteobacteria such as Mariprofundus ferrooxydans) that have been identified in these mats are likely supported by the advection of fluids containing $40-150 \mathrm{mM} \mathrm{Fe}$ (Glazer and Rouxel, 2009; Edwards et al., 2011). The reductive transformation of the Si-rich FhSRO would not be predicted to occur substantially 

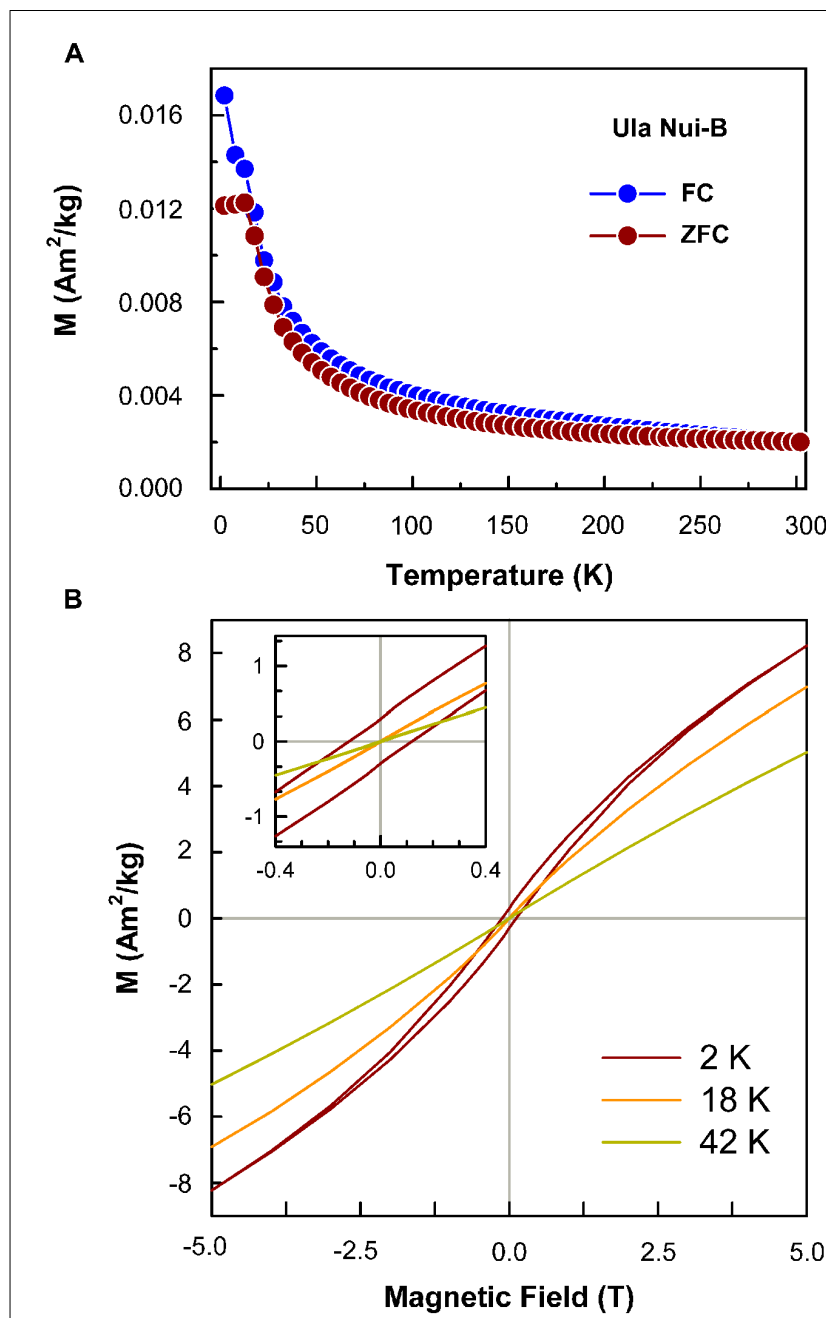

FIGURE 7 | Induced magnetization curves, ZFC/FC and hysteresis loops. (A) ZFC/FC curves typical of Loihi Fe mat samples. Above peak temperature the material behaves as a paramagnetic phase. Below the peak temperature the material has magnetic order. (B) The Hysteresis loops at variable temperature show the antiferromagnetic character of ferrihydrite, that is the non-saturation at high fields. At $2 \mathrm{~K}$ the coercive force is different of zero (see inset) and indicates the sample has magnetic order. At 18 and $42 \mathrm{~K} \mathrm{H}_{\mathrm{C}}$ is zero and indicates the sample is in the superparamagnetic state.

under these low Fe fluxes, and therefore the EXAFS signature of $\mathrm{Fe}(\mathrm{III})$ in the $\mathrm{Fh}_{\mathrm{SRO}}$ dominates these samples. The Fe(II)-rich zones shown in R2 of Figure 2 occur several millimeters below the surface of the mat where oxygen concentrations drop to only a few micromolar; the $\mathrm{Fe}(\mathrm{II})$-mineralization may represent regions of localized microbial Fe-reduction using fixed organic carbon (e.g., filaments and extracellular material) resulting in the precipitation of $\mathrm{Fe}$ (II)-rich phases such as carbonates or sulfides. Given the strong co-localization between $\mathrm{Fe}$ (II) and $\mathrm{Ca}$ in this region of the mat, carbonates are the most likely candidate phase, but Fe K-edge XANES were not collected in this region for quantitative analysis. Although 16S rRNA sequences of DNA extracted from Ula Nui mats has not been reported, and enrichments for $\mathrm{Fe}$ (III)-reducing bacteria from Ula Nui have been unsuccessful (D. Emerson, personal communication), the potential presence and
Table 4 | Peak temperature obtained from ZFC curves and the corresponding particle size estimate using Néel-Arrhenius law.

\begin{tabular}{lll}
\hline Sample & $\boldsymbol{T}_{\mathbf{P}}(\mathbf{K})$ & Particle size (nm) \\
\hline Ula Nui-A & 10 & 3.5 \\
Ula Nui-B/C & 12 & 3.7 \\
Lohiau A & 19 & 4.3 \\
Spillway A & 21 & 4.4 \\
Lohiau C & 22 & 4.5 \\
Tower & 24 & 4.6 \\
Hiolo A & 23 & 4.6 \\
\hline
\end{tabular}

Table 5 | Magnetic hyperfine parameters fitted at room temperature and $4.2 \mathrm{~K}$.

\begin{tabular}{|c|c|c|c|c|}
\hline & & $B_{\mathrm{HF}}(\mathrm{T})$ & $\mathrm{OS}(\mathrm{mm} / \mathrm{s})$ & IS $(\mathrm{mm} / \mathrm{s})$ \\
\hline \multirow[t]{2}{*}{ Hiolo A } & $300 \mathrm{~K}$ & - & $0.88(1)$ & $0.36(1)$ \\
\hline & $4.2 \mathrm{~K}$ & $46.0(2)$ & $-0.02(1)$ & $0.53(1)$ \\
\hline \multirow[t]{2}{*}{ Ula Nui-B/C } & $300 \mathrm{~K}$ & - & $0.84(1)$ & $0.36(1)$ \\
\hline & $4.2 \mathrm{~K}$ & $44.4(4)$ & $-0.02(1)$ & $0.53(1)$ \\
\hline
\end{tabular}

Magnetic hyperfine field $\left(B_{H F}\right)$, quadrupole splitting (OS), isomer shift (IS), errors are quoted in parenthesis.

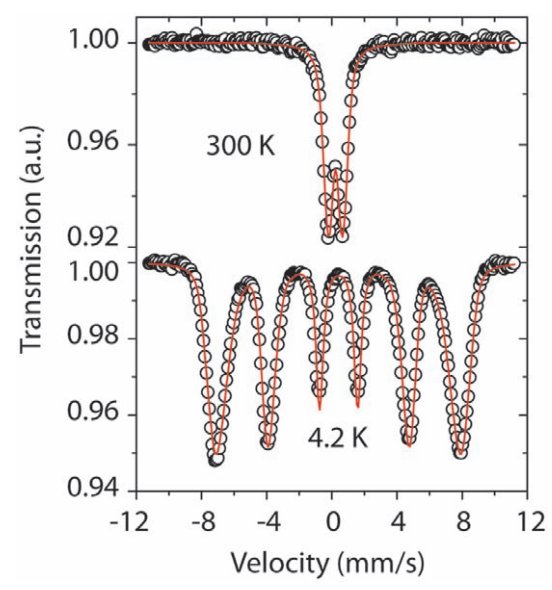

FIGURE 8 |The Mössbauer spectra show the typical behavior of Loihi $\mathbf{F h}_{\text {sRo }}$. At room temperature the spectrum is represented by a doublet and indicates the presence of $\mathrm{Fe}^{3+}$. At $4.2 \mathrm{~K}$ the spectrum is a sextet and indicates magnetic order. The sextet has broad lines suggesting the Fe phase is poorly crystallized. The doublet at room temperature represents a phase in a superparamagnetic state.

activity of Fe-reducing bacteria is plausible given the isolation of $\mathrm{Fe}$ (III)-reducing bacteria from Fe mats at the Loihi summit (Bailey et al., 2009; Emerson, 2009) and the thermodynamic favorability of coupling organic matter oxidation to $\mathrm{Fe}(\mathrm{III})$-reduction within interior anoxic portions of these mats. Reduction of biogenic Fe oxides has also been demonstrated at the Tonga-Kermadec Arc (Langley et al., 2009).

The local coordination environment of $\mathrm{Fe}$ (III) in the Loihi mats was compared to a reference library of Fe oxyhydroxide phases 


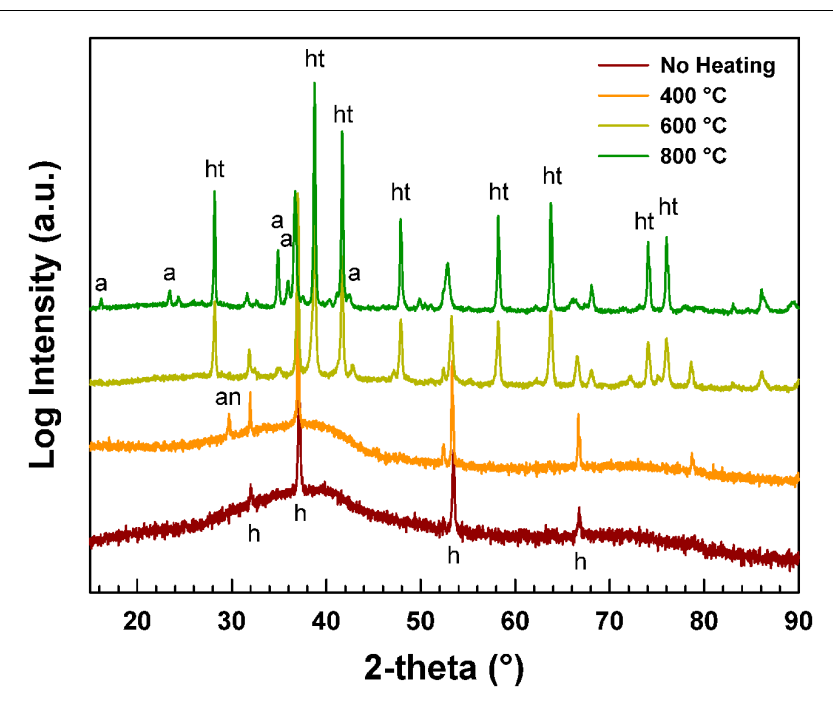

FIGURE 9 | X-ray diffraction pattern of Loihi sample before and after thermal treatment. The pattern obtained with no heat treatment and treatment at $400^{\circ} \mathrm{C}$ have only two broad lines similar to the pattern of material without treatment. In the 600 and $800^{\circ} \mathrm{C}$ treatments, the sharp lines correspond to hematite and the broad lines of Fh are no longer present. Aegerine "a," anhydrite "an," hematite "ht," and halite "h."

(Figure 1), and found to be most similar to that of a deep-sea, biogenic Fe oxyhydroxide (seafloor incubation of sulfide minerals at Juan de Fuca Ridge; Toner et al., 2009). Within our dataset, the Fe mat from Pohaku hosts the only phase matching the standard two-line Fh. The most important difference between the Loihi mat spectra and that of the two-line Fh standard is in the $k$-range $=7-$ $8 \AA^{-1}$, where the peak at $k=7.5 \AA^{-1}$ is greatly reduced in mat spectra relative to two-line Fh (except for Pohaku). Mikutta (2011) recently reported a similar observation for synthetic Fh formed in the presence of varying amounts of organic ligands and attributed the decrease in intensity of this feature with increasing L/Fe ratio to a reduced number of nearest Fe neighbors. Iron EXAFS spectra with characteristics similar to the Loihi $\mathrm{Fh}_{\mathrm{SRO}}$ are reported in the presence of Si (Masion et al., 2001; Doelsch et al., 2003; Voegelin et al., 2010; Boland et al., 2011), P (Rose et al., 1997; Voegelin et al., 2010), and organic molecules (Vilge-Ritter et al., 1999; Mikutta, 2011). While the organic $C$ content of the mats is low ( $\sim 0.3 \mathrm{wt}$. $\%)$, the Si:Fe mole ratio for the Fe-rich mats is $0.107-0.298$, and the P:Fe ratio is 0.0280-0.168 (Table 2). Based on these EXAFS observations, we hypothesize that $\mathrm{Si}$, and perhaps $\mathrm{P}$, is reducing the degree of structural order in Loihi Seamount natural Fh $\mathrm{SRO}_{\mathrm{S}}$ phases to an extent less than that typically observed for synthetic two-line Fh. In addition, we propose that the natural FhSRO we detect in all but one Loihi Fe mat is preserved from recrystallization to Fh or other Fe oxyhydroxides such as goethite by the presence of inorganic ligands ( $\mathrm{Si}, \mathrm{P})$.

Consistent with $\mathrm{Fe}(\mathrm{III})$ polymerization in the presence of strongly sorbing ligands, Mössbauer spectroscopy reveals that the Loihi Seamount FhsRO phases have more structural defects than synthetic Fh. This is observed as a decrease in the magnetic hyperfine field $\left(B_{\mathrm{HF}}\right)$. Ferrihydrite, specifically two-line Fh, has significant defects in both the tetrahedral and octahedral Fe(III)

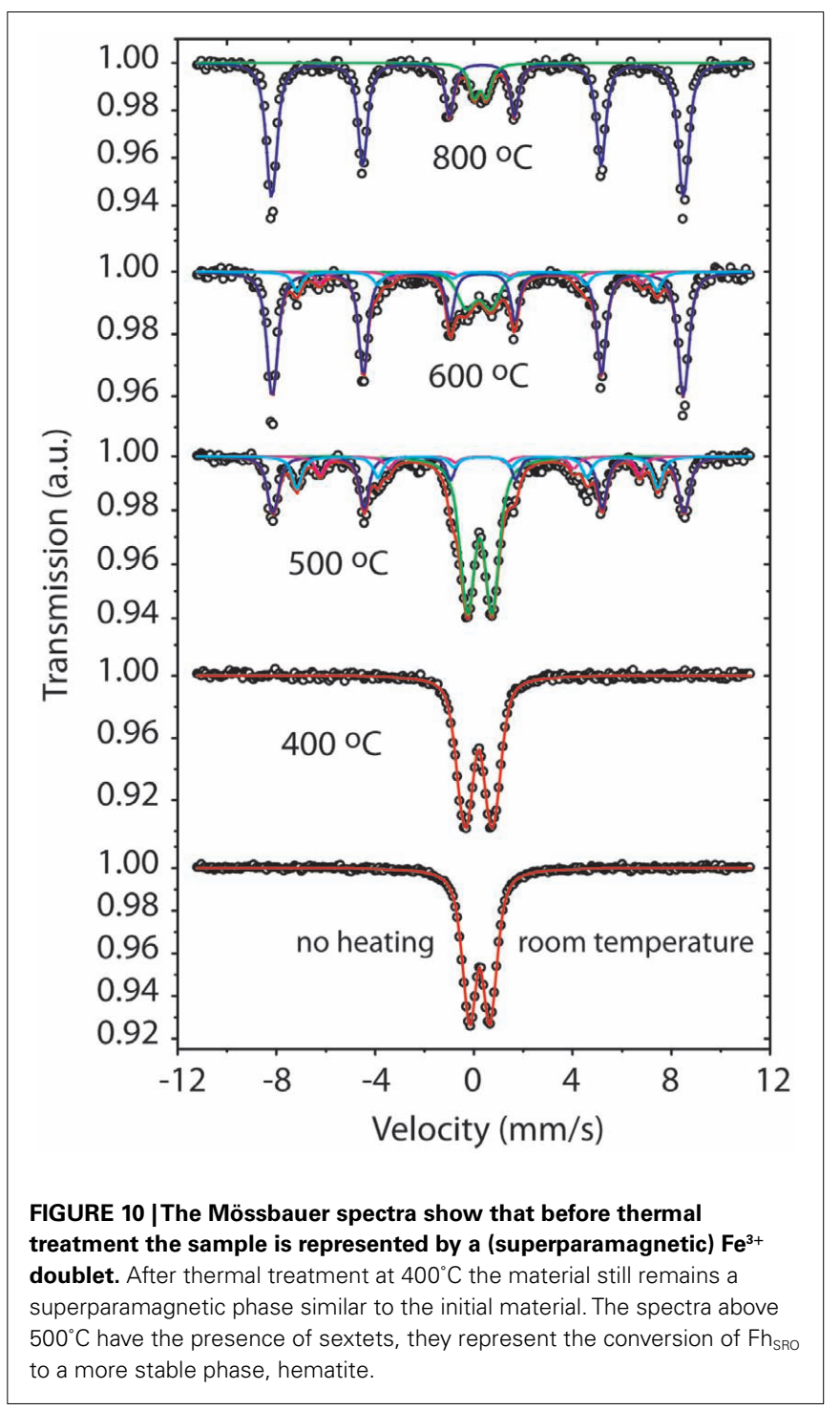

sites (Michel et al., 2010), and these natural FhSRO samples from Loihi Seamount seem to have extra Fe(III)-site lattice defects due perhaps to Fe substitution and vacancies.

The SR-XRD (Figure 3) and total X-ray scattering data in the form of reduced structure functions (Figure 4) reveal that the high- $Q$ (i.e., high angle) scattering maxima for the five natural mat samples are similar, but not identical, to the synthetic two-line Fh reference. In the case of BT37, Spillway A, and Lohiau A (Tables 1 and 2), the samples with the most clearly resolvable fraction of natural $\mathrm{Fh}_{\mathrm{SRO}}$, the comparison to pure synthetic Fh suggests that these samples bear some structural similarities. Comparison of the PDFs for these samples confirms similarities in short- and intermediaterange structure and provides further insight as to the structural association of $\mathrm{Si}$ and $\mathrm{Fe}$ in the nanostructured matrix (Figures 5 and 6).

The Si:Fe mole ratio measured for the mats by ICP-OES are $0.245,0.107$, and 0.207 , respectively. The total measured Si:Fe mole ratios for Ula Nui-A and Ula Nui-B/C mats are 0.289 and 0.227 , respectively (Table 2 ). Assuming that these samples are primarily 
single-phase, the differences in the region of the PDFs between $2.5<r<4 \AA$ (Figure 5) suggest that $\mathrm{Si}$ is predominantly associated with the $\mathrm{Fh}_{\mathrm{SRO}}$ surfaces, perhaps in the form of a poorly ordered silica coating. Alternatively, in the case that these samples are multi-phasic then the observed PDFs could also be explained by at least two phases; one comprised of a Fh-like core, perhaps with a Si-rich coating, and a second comprised of an Fe-bearing amorphous $\mathrm{SiO}_{2}$ phase, similar to that observed by Pokrovski et al. (2003). Either scenario would also be consistent with the observation that features at higher $r(>4 \AA)$ in the PDFs show a return to Fh-like ordering, albeit with smaller CSD sizes. In addition, although the correlations attributable to edge- and corner-sharing Fe polyhedra at $\sim 3.03$ and $3.44 \AA$, respectively, are not clearly delineated in the PDFs for the mat samples it is possible that they exist but are obscured by other pair correlations involving Si. As discussed above, further evidence for the presence of edge-sharing Fe polyhedra is indicated by the EXAFS for all the Loihi mats. The presence of such polyhedral connectivity would be required in order to produce the intermediate-range Fh-like ordering observed in the region $4<r<\sim 12 \AA$ (Figure A3 in Appendix). Structural information over these longer distances would not be available from previous (and present) EXAFS results since the range of inter-atomic distances measured, particularly in the case of Fh, are typically less than $\sim 4-5 \AA$. In summary, the PDFs indicate the presence of limited intermediate-range Fh-like structural ordering, which suggests that silica is not structurally incorporated in ferrihydrite. Differences in short-range ordering of the natural samples relative to $\mathrm{Si}$-free Fh suggest that the Fh particles are coated with Si.

\section{PARTICLE DIMENSIONS AND INTERACTIONS OF IRON-BEARING PHASES}

The magnetic behavior of the Loihi Seamount Fh $\mathrm{SRO}$ was evaluated since particle coatings such as Si or organic matter are expected to diminish or completely inhibit magnetic interactions of antiferromagnetic Fe oxyhydroxides. In a superparamagnetic system when particles are cooled without an applied field, the magnetic moments are randomly oriented and the resulting induced magnetization is around zero at $0 \mathrm{~K}$. With increasing temperature of the system and in the presence of an external applied field, the magnetic moments begin to fluctuate, then align in the direction of the external field, leading to an increase of the total magnetization (Chantrell et al., 1991; Dormann et al., 1997) and a peak is observed in the ZFC curve (Figure 7). Above the peak temperature $\left(T_{\mathrm{P}}\right)$ the thermal energy of disorder is higher than the ordering energy and a superparamagnetic behavior results, leading to a decrease of the total magnetization with increasing temperature following the Curie-Weiss law. The presence of a maximum in the ZFC curve is therefore associated with the transition between magnetically relaxing superparamagnetic (unblocked state) and thermally stable magnetization (blocked state). The FC curve represents the superparamagnetic system cooled down in the presence of an external magnetic field.

Current models suggest that particle coatings prevent magnetic interactions for antiferromagnetic systems (Berquó et al., 2009), although this may not prevent magnetic interactions for ferrimagnetic phases such as maghemite and magnetite. Since Fh particles are antiferromagnetic, we apply the antiferromagnetic model to understand Loihi ZFC/FC curves. Berquó et al. (2009) verified that synthetic agglomerated Fh particles, without coating and magnetically interacting, showed a $T_{\mathrm{P}}$ shifted to higher temperatures as compared with the same particles coated, thus considered without magnetic interactions. The $T_{\mathrm{P}}$ estimated from ZFC curves of Loihi samples are similar to the ones obtained by Berquó et al. (2009) for coated synthetic Fh, and this result strongly suggests that the natural $\mathrm{Fh}_{\mathrm{SRO}}$ particles are also individually wrapped in a way that prevents magnetic interactions. The coating agents that could create this magnetic masking include organic matter or $\mathrm{Si}$ in the environment where the particles precipitate. The Loihi Seamount Fe mats are enriched in Si, and Si bonding to the natural $\mathrm{Fh}_{\mathrm{SRO}}$ is well supported by our X-ray scattering data and analysis. In addition to agreeing with complementary data, this result makes it possible to obtain a better estimate of magnetic particle size (Table 4) considering that there is no shift in the peak temperature due to magnetic interaction. The ZFC peak reflects exclusively the changes in particle volume without undesired effects that may contribute to its shift.

Differences in the particle size estimates from low-temperature magnetic data and the CSD sizes from PDF analysis for samples Ula Nui-A, Ula Nui-B, Lohiau A, and Spillway A are evident (Table 4) and point toward the presence of structural disorder in the natural $\mathrm{Fh}_{\mathrm{SRO}}$. These two types of data can be considered as complementary in the sense that the low-temperature magnetic data indicate an upper limit for the maximum physical dimensions of the particles, while the PDF reveals the average dimensions over which the atoms in the structure scatter coherently. It is possible for the CSD to equal the particle size, but this is not always the case, in particular for Fh (e.g., Michel et al., 2008). In principal, for a monodisperse nanocrystalline material (i.e., with virtually no structural disorder), the PDF peaks decay as $r$ approaches the average maximum dimensions of the particle; therefore, particle size and CSD size are effectively equal. For highly disordered or amorphous structures, the CSD size can be substantially smaller than the physical size of the particles due to the effects of static/dynamic disorder, which attenuate the features in the PDF at higher $r$. It is worth noting that it becomes increasingly difficult to correlate CSD size with actual particle size, in particular for natural samples, from PDF data alone since the CSD size estimates become increasingly uncertain for polydisperse materials and/or if multiple structural phases are present, as is the case for natural samples Ula Nui-A and -B. However, for Lohiau A and Spillway A, natural samples that are dominantly $\mathrm{Fh}_{\mathrm{SRO}}$, the observed discrepancy between average particle size and CSD size suggests strongly that these samples have intrinsic static and dynamic forms of structural disorder. Past studies of pure synthetic Fh (Michel et al., 2010; Cismasu et al., 2011) have suggested that the bulk structure exhibits size-dependent lattice strain and defects in the form of vacancies. In addition, sizeand defect-driven restructuring of the Fh surfaces is also possible, although poorly understood at present. Evidence for lattice strain and structural defects in natural $\mathrm{Fh}_{\mathrm{SRO}}$ is difficult to discern in the present case due, in part, to the presence of minor crystalline impurity phases such as birnessite. Additional complexity due to the presence of compositional impurities and/or adsorbed species such as silica or organic matter are also factors and may account 
for the discrepancies between average coherent scattering body size and particle size.

\section{PARTICLE STABILITY OF IRON-BEARING PHASES}

The local coordination of Fe in Loihi mats was remarkably insensitive to sample processing, storage, and handling procedures such as freezing, drying, and storage in seawater up to 1 year (Figure 1; Figures $\mathbf{A} 1$ and $\mathbf{A} 2$ in Appendix). The short-range order of the Naha and Lohiau Fe mats (Figure A1 in Appendix; data not shown for Lohiau) did not change after aging for 1 year at $4^{\circ} \mathrm{C}$. Although the $\mathrm{Fh}_{\mathrm{SRO}}$ phases might be expected to transform to more stable minerals such as goethite (Penn et al., 2006), no recrystallization was observed. The stability of the local structure of the $\mathrm{Fh}_{\mathrm{SRO}}$ as a function of time and temperature is consistent with non-interacting particles. In addition, the Loihi Seamount Fe mats did not convert to the more stable hematite phase during a $400^{\circ} \mathrm{C}$ thermal treatment. Pure Fh is expected to rapidly convert to hematite between 300 and $400^{\circ} \mathrm{C}$ (Cornell and Schwertmann, 2003). However, surface coatings on Fh, such as adsorbed Si or organic molecules, are known to slow or inhibit its transformation to crystalline products (Cornell and Schwertmann, 1979; Anderson and Benjamin, 1985; Campbell et al., 2002). Stable Fe minerals such as goethite were not observed at any of the Loihi field sites or under any of the experimental conditions below $400^{\circ} \mathrm{C}$. All EXAFS, PDF, and magnetism data from the present study point to Si particle coatings that limit chemical interactions among natural $\mathrm{Fh}_{\mathrm{SRO}}$ particles in Loihi mats.

In addition to limited particle-particle interactions, chemical, and biological reactions involving $\mathrm{Fe}(\mathrm{II})$ may be limited in Loihi mats and contribute to stability of the $\mathrm{Fh}_{\mathrm{SRO}}$. The low activity of Fe-reducing bacteria in Loihi mats suggests that the Fh SRO $_{\text {phases }}$ are not subject to intense biological reductive alteration (Emerson, 2009), although some Fe-reducing bacteria are known to solubilize Fe(II) from Si-enriched Fh (Percak-Dennett et al., 2011). Despite the constant source of $\mathrm{Fe}$ (II) to all but the "dead" Naha site, $\mathrm{Fe}(\mathrm{II})$ induced reduction of $\mathrm{Fh}_{\mathrm{SRO}}$ may be negligible based on results from synthetic Si-enriched Fh studies (Jones et al., 2009; Boland et al., 2011). For example, Si:Fe ratios of 0.7 have been shown to inhibit $\mathrm{Fe}(\mathrm{II})$-induced recrystallization of $\mathrm{Fh}$ to goethite at pH 6.5 (Boland et al., 2011). However, the data presented here does not address the potential for exchange between vent fluid $\mathrm{Fe}(\mathrm{II})$ and $\mathrm{Fe}_{\mathrm{SRO}}$, and there is evidence that Si-enriched Fh phases retain chemical reactivity. For example, Si:Fe mole ratios up to 0.5 can be achieved without blocking all reactive Fh surface sites due to surface-bound silicate oligomers (Swedlund et al., 2009). In addition, Si-enriched Fh phases are soluble in the presence of organic molecules, such as oxalate and acetate (Carlson and Schwertmann, 1981; Percak-Dennett et al., 2011). We speculate that the low organic carbon content of the Loihi mats may limit both biological and chemical reductive dissolution reactions. These factors combined suggest that the $\mathrm{Fe}_{\mathrm{SRO}}$ signatures observed at Loihi may be resistant to diagenetic processes and persist over long periods of time.

\section{IRON MICROBIAL MATS AT DIFFUSE HYDROTHERMAL VENTS}

Iron and Si-rich microbial mats are observed in shallow and deep marine hydrothermal systems. The number of published observations of Fe microbial mats indicates that these deposits may be common features associated with diffuse venting. Diffuse hydrothermal vents at seamounts and submarine volcanoes associated with island arcs and mid-ocean ridge spreading centers host $\mathrm{Fe}$ (and Si) microbial mats, for example: Loihi Seamount (Karl et al., 1988; Edwards et al., 2011), Vailulu'u Seamount (Sudek et al., 2009); Giggenbach Volcano, Kermadec Arc (Jones et al., 2008); Axial Volcano, Juan de Fuca Ridge (Kennedy et al., 2003); South Tonga Arc volcanoes (Langley et al., 2009; Forget et al., 2010); Lilliput vent field, Mid-Atlantic Ridge (Dekov et al., 2010). Among these studies, the Fe mineralogy, when reported, is resoundingly "amorphous" Fe oxyhydroxide, ferrihydrite, and occasionally goethite. A recent review of the microbiology of active seamount $\mathrm{Fe}$ microbial mats indicates that Zeta-proteobacteria and/or Epsilonproteobacteria are shared among sites (Emerson and Moyer, 2010), even though inter-site diversity is high (Davis and Moyer, 2008). A cultured representative of the Zeta-proteobacteria from Loihi Seamount (Emerson et al., 2007), M. ferrooxydans, is an Fe oxidizer that produces ferrihydrite-like phases in fresh filaments of twisted stalks (Chan et al., 2011). Frequent observations of Fe-encrusted filamentous structures at diffuse vents, and the apparent ubiquity of Zeta-proteobacteria in the mats, suggest that Loihi Seamount mats may represent common depositional environments at the modern seafloor. The present study indicates that the presence of $\mathrm{Si}$ and organic templates are both primary geochemical factors in the structure of Fe-bearing phases as well as the preservation of the phases as a function of time and temperature.

\section{CONCLUSION}

Certain characteristics of Fe oxyhydroxide phases - particle size, crystallinity - are known to respond to solution conditions such as $\mathrm{Si}$ concentration, as well as factors that influence the rate of precipitation, such as temperature and $\mathrm{pH}$ (Cornell and Schwertmann, 2003). The overarching goal for this study is to determine whether Fe oxyhydroxide phases can be used to interpret the biogeochemical conditions of past depositional settings. In particular, we are concerned with whether the characteristics of fresh Fe oxyhydroxide phases are preserved over time. As a first step toward this goal, we examined the Fe-rich, flocculant microbial mats hosted by active (and recently active) vents of the Loihi Seamount. The mats are composed of nanoparticulate ferrihydrite (Fh)-like phases with short-range structural order $\left(\mathrm{Fh}_{\mathrm{SRO}}\right)$ at all but one site (Pohaku) irrespective of depth or temperature. The Loihi Fh ${ }_{\mathrm{SRO}}$ are primarily $\mathrm{Fe}(\mathrm{III})$ with little particle-to-particle variability in the local coordination environment of $\mathrm{Fe}$ within a single mat; although careful sampling of the Ula Nui site revealed isolated microzones of solid-phase $\mathrm{Fe}$ (II)-enrichment beneath the mat-seawater interface. For our entire sample set, maximum particle diameters of $3.5-4.6 \mathrm{~nm}$ (magnetism data) were found to be positively correlated with maximum vent fluid temperature, while CSD sizes (PDF analysis) as small as $1.6 \mathrm{~nm}$ were observed, and are inversely correlated with vent fluid temperature. These data indicate that the Loihi $\mathrm{Fh}_{\text {SRO }}$ phases have intrinsic static and dynamic forms of structural disorder, likely from lattice strain and vacancy or substitutional impurity defects. Magnetic data and PDF analysis both point to $\mathrm{Fh}_{\text {SRO }}$ particles coated by Si. The Loihi mat $\mathrm{Fh}_{\mathrm{SRO}}$ phases did not transform to other Fe mineral phases in response to freezing, drying, aging in seawater for up to 1 year, or standard heat treatments under oxic conditions. We hypothesize that $\mathrm{Si}$ increases 
structural disorder and decreases CSD sizes in Loihi Seamount mats, and propose that the natural $\mathrm{Fh}_{\mathrm{SRO}}$ we detect is preserved from recrystallization to $\mathrm{Fh}$, or other Fe oxyhydroxides such as goethite, by the presence of $\mathrm{Si}$, although $\mathrm{P}$ and organic molecules could potentially contribute.

\section{ACKNOWLEDGMENTS}

We thank Clara Chan (University of Delaware) for mat collection during the 2006 cruise, and R. Lee Penn (University of Minnesota) for use of the X-ray diffractometer. We thank Matthew Marcus and Sirine Fakra (Advanced Light Source 10.3.2), Dale Brewe and Steve Heald (Advanced Photon Source 20-BM), and Kevin Beyer (Advanced Photon Source 11-ID-B) for synchrotron support. We thank Sarah Bennett, Cara Santelli, Beth Orcutt, and Amanda Turner Haddad for assistance in synchrotron data collection. F. Marc Michel is supported by the DOE Office of Biological and Environmental Research through the Science Focus Area at the Stanford Synchrotron Radiation Lightsource (SSRL), SLAC National Accelerator Laboratory, Stanford University, and by the National Science Foundation (NSF) and the Environmental

\section{REFERENCES}

Anderson, P. R., and Benjamin, M. M. (1985). Effects of silicon on the crystallization and adsorption properties of ferric oxides. Environ. Sci. Technol. 19, 1048-1053.

Bailey, B., Templeton, A. S., Staudigel, H., and Tebo, B. M. (2009). Utilization of substrate components during basaltic glass colonization by Pseudomonas and Shewanella isolates. Geomicrobiol. J. 26, 648-656.

Berquó, T. S., Erbs, J. J., Lindquist, A., Penn, R. L., and Banerjee, S. K. (2009). Effects of magnetic interactions in antiferromagnetic ferrihydrite particles. J. Phys. Condens. Matter 21, 176005.

Boland, D. D., Collins, R. N., Payne, T. E., and Waite, T. D. (2011). Effect of amorphous $\mathrm{Fe}$ (III) oxide transformation on the $\mathrm{Fe}(\mathrm{II})$-mediated reduction of $\mathrm{U}(\mathrm{VI})$. Environ. Sci. Technol. 45, 1327-1333.

Brand, R. A. (1987). Improving the validity of hyperfine field distributions from metallic alloys. Part I: unpolarized source. $\mathrm{Nucl}$. Instrum. Methods Phys. Res. B 28, 398-405.

Campbell, A. C. (1991). "Mineralogy and chemistry of marine particles by synchrotron X-ray spectroscopy, Mossbauer spectroscopy, and plasma-mass spectrometry," in Marine Particles: Analysis and Characterization, Vol. 63, Geophysical Monograph Series, eds D. C. Hurd and D. W. Spencer (Washington: American Geophysical Union), 375-390.

Campbell, A. S., Schwertmann, U., Stanjek, H., Friedl, J., Kyek, A., and Campbell, P. A. (2002). Si incorporation into hematite by hearing Si-ferrihydrite. Langmuir 18, 7804-7809.

Carlson, L., and Schwertmann, U. (1981). Natural ferrihydrites in surface deposits from Finland and their association with silica. Geochim. Cosmochim. Acta 45, 421-429. Fleming, E. J., and Edwards, K. J. (2011). Lithotrophic iron-oxidizing bacteria produce organic stalks to control mineral growth: implications for biosignature formation. ISME J. 5, 717-727.

Chan, C. S., Stasio, G. D., Welch, S. A., Girasole, M., Frazer, B. H., Nesterova, M. V., Fakra, S., and Banfield, J. F. (2004). Microbial polysaccharides template assembly of nanocrystal fibers. Science 303, 1656-1658.

Chantrell, R. W., El-Hilo, M., and O'Grady, K. (1991). Spin-glass behavior in a fine particle system. IEEE Trans. Magn. 27, 3570-3578.

Chupas, P. J., Qui, X., Hanson, J. C., Lee, P. L., Grey, C. P., and Billinge, S. J. L. (2003). Rapid-acquisition pair distribution function (RA-PDF) analysis. J. Appl. Crystallogr. 36, 1342-1347.

Cismasu, A. C., Michel, F. M., Tcaciuc, A. P., Tyliszczak, T., and Brown, G. E. J. (2011). Composition and structural aspects of naturally occurring ferrihydrite. C. R. Geosci. 343, 210-218.

Cornell, R. M., and Schwertmann, U. (1979). Influence of organic anions on the crystallization of
Chan, C. S., Fakra, S. C., Emerson, D.,

Protection Agency (EPA) under NSF Cooperative Agreement EF0830093 through the Center for Environmental Implications of NanoTechnology (CEINT). The Institute for Rock Magnetism (IRM) is funded by the W. M. Keck Foundation, the Earth Science Division of the US National Science Foundation (NSF/EAR 0732473 and NSF/EAR 1028690), and the University of Minnesota. This is IRM contribution \#1109. The Advanced Light Source is supported by the Director, Office of Science, Office of Basic Energy Sciences, of the U.S. Department of Energy under Contract No. DE-AC02-05CH11231. Use of the Advanced Photon Source, an Office of Science User Facility operated for the U.S. Department of Energy (DOE) Office of Science by Argonne National Laboratory, was supported by the U.S. DOE under Contract No. DE-AC02-06CH11357. Alexis S. Templeton also acknowledges SSRL, an Office of Science User Facility operated by the U.S. Department of Energy Office of Science by Stanford University. The SSRL Structural Molecular Biology Program is supported by the DOE Office of Biological and Environmental Research, and by the National Institutes of Health, National Center for Research Resources, Biomedical Technology Program (PR1RR001209).

ferrihydrite. Clays Clay Miner. 27, 402-410.

Cornell, R. M., and Schwertmann, U. (2003). The Iron Oxides: Structure, Properties, Reactions, Occurrences and Uses. Darmstadt: Wiley$\mathrm{VCH}$.

Davis, R. E., and Moyer, C. L. (2008). Extreme spatial and temporal variability of hydrothermal microbial mat communities along the Mariana Island Arc and southern Mariana back-arc system. J. Geophys. Res. $113,1-17$.

DeCarlo, E. H., McMurtry, G. M., and Yeh, H.-W. (1983). Geochemistry of hydrothermal deposits from the Loihi submarine volcano, Hawaii. Earth Planet. Sci. Lett. 66, 438-449.

Dekov, V. M., Petersen, S., GarbeSchonberg, C. D., Kamenov, G. D., Perner, M., Kuzmann, E., and Schmidt, M. (2010). Fe-Sioxyhydroxide deposits at a slowspreading centre with thickened oceanic crust: the Lilliput hydrothermal field (9 degrees 33' S, MidAtlantic Ridge). Chem. Geol. 278, 186-200.

Doelsch, E., Masion, A., Rose, J., Stone, W. E. E., Bottero, J. Y., and Bertsch, P. M. (2003). Chemistry and structure of colloids obtained by hydrolysis of $\mathrm{Fe}(\mathrm{III})$ in the presence of $\mathrm{SiO}_{4}$ ligands. Colloids Surf. A Physicochem. Eng. Asp. 217, 121-128.

Dormann, J. L., Fiorani, D., and Tronc, E. (1997). "Magnetic relaxation in fine-particle systems," in Advances in Chemical Physics, Vol. XCVIII, eds I. Prigogine and S. A. Rice (New York: Wiley), 283-494.
Drits, V. A., Sakharov, B. A., Salyn, A. L., and Manceau, A. (1993). Structural model for ferrihydrite. Clay Miner. 28, 185-207.

Druschel, G. K., Emerson, D., Sutka, R., Suchecki, P., and Luther, G. W. III. (2008). Low-oxygen and chemical kinetic constraints on the geochemical niche of neutrophilic iron(II) oxidizing microorganisms. Geochim. Cosmochim. Acta 72, 3358-3370.

Duarte, E. L., Itri, R., Lima, E. J., Baptista, M. P., Berquo, T. S., and Goya, G. F. (2006). Large magnetic anisotropy in ferrihydrite nanoparticles synthesized from reverse micelles. Nanotechnology 17, 5549-5555.

Edwards, K. J., Glazer, B. T., Rouxel, O. J., Bach, W., Emerson, D., Davis, R. E., Toner, B. M., Chan, C. S., Tebo, B. M., Staudigel, H., and Moyer, C. L. (2011). Ultra-diffuse hydrothermal venting supports Fe-oxidizing bacteria and massive umber deposition at 5000 off Hawaii. ISME J. 5, 1-11.

Edwards, K. J., McCollom, T. M., Konishi, H., and Buseck, P. R. (2003). Seafloor bioalteration of sulfide minerals: results from in situ incubation studies. Geochim. Cosmochim. Acta 67, 2843-2856.

Egami, T., and Billinge, S. J. L. (2003). Underneath the Bragg Peaks: Structural Analysis of Complex Materials. Oxford: Elsevier, 1-404.

Ekstrom, E. B., Learman, D. R., Madden, A. S., and Hansel, C. M. (2010). Contrasting effects of Al substitution on microbial reduction of $\mathrm{Fe}$ (III) (hydr)oxides. Geochim. Cosmochim. Acta 74, 7086-7099. 
Emerson, D. (2009). Potential for ironreduction and iron-cycling in iron oxyhydroxide-rich microbial mats at Loihi Seamount. Geomicrobiol. J. 26, 639-647.

Emerson, D., and Moyer, C. L. (2002). Neutrophilic Fe-oxidizing bacteria are abundant at the Loihi Seamount hydrothermal vents and play a major role in $\mathrm{Fe}$ oxide deposition. Appl. Environ. Microbiol. 68, 3085-3093.

Emerson, D., and Moyer, C. L. (2010). Microbiology of seamounts: common patterns observed in community structure. Oceanography 23, 148-163.

Emerson, D., Rentz, J. A., Lilburn, T. G., Davis, R. E., Aldrich, H., Chan, C., and Moyer, C. L. (2007). A novel lineage of proteobacteria involved in formation of marine Fe-oxidizing microbial mat communities. PLoS ONE 2, e667. doi:10.1371/journal.pone.0000667

Emerson, D., and Revsbech, N. P. (1994). Investigation of an ironoxidizing microbial mat community located near Aarhus, Denmark: field studies. Appl. Environ. Microbiol. 60, 4022-4031.

Erbs, J., Gilbert, B., and Penn, R. L. (2008). Influence of size on reductive dissolution of six-line ferrihydrite. $J$. Phys. Chem. C 112, 12127-12133.

Forget, N. L., Murdock, S. A., and Juniper, S. K. (2010). Bacterial diversity in Fe-rich hydrothermal sediments at two South Tonga Arc submarine volcanoes. Geobiology 8, 417-432.

Gilbert, B. (2008). Finite size effects on the real-space pair distribution function of nanoparticles. J. Appl. Crystallogr. 41, 554-562.

Gilles, C., Bonville, P., Wong, K. K. W., and Mann, S. (2000). Non-Langevin behaviour of the uncompensated magnetization in nanoparticles of artificial ferritin. Eur. Phys. J. B 17, 417-427.

Glazer, B. T., and Rouxel, O. J. (2009). Redox speciation and distribution within diverse irondominated microbial habitats at Loihi Seamount. Geomicrobiol. J. 26, 606-622.

Grimley, D. I., Wright, A. C., and Sinclair, R. N. (1990). Neutronscattering from vitreous silica.4. Time-of-flight diffraction. J. Non Cryst. Solids 119, 49-64.

Guinier, A. (1963). X-Ray Diffraction in Crystals, Imperfect Crystals, and Amorphous Bodies. San Francisco: W. H. Freeman.

Hall, B. D., Zanchet, D., and Ugarte, D. (2000). Estimating nanoparticle size from diffraction measurements. J. Appl. Crystallogr. 33, 1335-1341.

Hammersley, A. P., Svenson, S. O. Hanfland, M., and Hauserman, D. (1996). Two-dimensional detector software: from real detector to idealised image or two-theta scan. High Press. Res. 14, 235-248.

Hansel, C. M., Benner, S. G., Neiss, J., Dohnalkova, A., Kukkadapu, R. K., and Fendorf, S. (2003). Secondary mineralization pathways induced by dissimilatory iron reduction of ferrihydrite under advective flow. Geochim. Cosmochim. Acta 67, 2977-2992.

Hansel, C. M., Learman, D. R., Lentini, C. J., and Ekstrom, E. B. (2011) Effect of adsorbed and substituted $\mathrm{Al}$ on $\mathrm{Fe}(\mathrm{II})$-induced mineralization pathways of ferrihydrite. Geochim. Cosmochim. Acta 75, 4653-4666.

Hirata, Y., Yoshitomi, A., and Sameshima, S. (2003). Reaction, microstructures and mechanical properties of model ceramic ware in the $\mathrm{K}_{2} \mathrm{O}-\mathrm{Al}_{2} \mathrm{O}_{3}-\mathrm{SiO}_{2}$ system. $J$. Ceram. Soc. Jpn. 111, 560-566.

Hochella, M. F. Jr., Lower, S. K., Maurice, P. A., Penn, R. L., Sahai, N., Sparks, D. L., and Twining, B. S. (2008). Nanominerals, mineral nanoparticles, and earth systems. Science 319, 1631-1634.

Jambor, J. L., and Dutrizac, J. E. (1998). Occurrence and constitution of natural and synthetic ferrihydrite, a widespread iron oxyhydroxide. Chem. Rev. 98, 2549-2585.

Janney, D. E., Cowley, J. M., and Buseck, P. R. (2000). Structure of synthetic 2line ferrihydrite by electron diffraction. Am. Mineral. 85, 1180-1187.

Jones, A. M., Collins, R. N., Rose, J., and Waite, T. D. (2009). The effect of silica and natural organic matter on the $\mathrm{Fe}$ (II)-catalysed transformation and reactivity of $\mathrm{Fe}$ (III) minerals. Geochim. Cosmochim. Acta 73, 4409-4422.

Jones, B., de Ronde, C. E. J., and Renaut, R. W. (2008). Mineralized microbes from Giggenbach submarine volcano. J. Geophys. Res. 113, 13.

Karl, D. M., Brittain, A. M., and Tilbrook, B. D. (1989). Hydrothermal and microbial processes at Loihi Seamount, a mid-plate hot-spot volcano. Deep Sea Res. 36, 1655-1673.

Karl, D. M., McMurtry, G. M., Malohoff, A., and Garcia, M. O. (1988). Loihi Seamount, Hawaii: a mid-plate volcano with a distinctive hydrothermal system. Nature 335, 532-535.

Kennedy, C. B., Scott, S. D., and Ferris, F. G. (2003). Characterization of bacteriogenic iron oxide deposits from Axial Volcano, Juan de Fuca Ridge,
Northeast Pacific Ocean. Geomicrobiol. J. 20, 199-214.

Klein, F. W. (1982). Earthquakes at Loihi submarine volcano and the Hawaiian hot spot. J. Geophys. Res. 87, 7719-7726

Langley, S., Igric, P., Takahashi, Y., Sakai, Y., Fortin, D., Hannington, M. D., and Schwarz-Schampera, U. (2009). Preliminary characterization and biological reduction of putative biogenic iron oxides (BIOS) from the Tonga-Kermadec Arc, southwest Pacific Ocean. Geobiology 7, 35-49.

Lorch, E. (1969). Neutron diffraction by germania silica and radiationdamaged silica glasses. J. Phys. C Solid State Phys. 2, 229.

Maillot, F., Morin, G., Wang, Y., Bonnin, D., Ildefonse, P., Chaneac, C. and Calas, G. (2011). New insight into the structure of nanocrystalline ferrihydrite: EXAFS evidence for tetrahedrally coordinated iron (III). Geochim. Cosmochim. Acta 75 2708-2720.

Manceau, A. (2009). Evaluation of the structural model for ferrihydrite derived from real-space modelling of high-energy X-ray diffraction data. Clay Miner. 44, 19-34.

Manceau, A. (2011). Critical evaluation of the revised akdalaite model for ferrihydrite. Am. Mineral. 96, 521-533.

Manceau, A., and Drits, V. A. (1993) Local structure of ferrihydrite and feroxyhite by EXAFS spectroscopy. Clay Miner. 28, 165-184.

Marcus, M. A., MacDowell, A., Celestre, R., Manceau, A., Miller, T., Padmore, H. A., and Sublett, R. E. (2004). Beamline 10.3.2 at ALS: a hard Xray microprobe for environmental and material sciences. J. Synchrotron Radiat. 11, 239-247.

Masion, A., Doelsch, E., Rose, J., Moustier, S., Bottero, J. Y., and Bertsch, P. M. (2001). Speciation and crystal chemistry of iron (III) chloride hydrolyzed in the presence of SiO4 ligands. 3. Semilocal scale structure of the aggregates. Langmuir 17, 4753-4757.

Mayhew, L. E., Webb, S. M., and Templeton, A. S. (2011). Microscale imaging and identification of $\mathrm{Fe}$ oxidation state, speciation, and distribution in complex geological media. Environ Sci. Technol. 45, 4468-4472.

Michel, F. M., Barrón, V., Torrent, J., Morales, M. P., Serna, C. J., Boily, J. F., Liu, Q. S., Ambrosini, A., Cismasu, A. C., and Brown, G. E. (2010). Ordered ferrimagnetic form of ferrihydrite reveals links among structure, composition, and magnetism. Proc. Natl. Acad. Sci. U.S.A. 107, 2787-2792.
Michel, F. M., Ehm, L., Antao, S. M., Lee, P. L., Chupas, P. J., Liu, G., Strongin, D. R., Schoonen, M. A. A., Phillips, B. L., and Parise, J. B. (2007a). The structure of ferrihydrite, a nanocrystalline material. Science 316, 1726-1729.

Michel, F. M., Ehm, L., Liu, G., Han, W. Q., Antao, S. M., Chupas, P. J., Lee, P. L., Knorr, K., Eulert, H., Kim, J., Grey, C. P., Celestian, A. J., Gillow, J., Schoonen, M. A. A., Strongin, D. R., and Parise, J. B. (2007b). Similarities in 2- and 6-line ferrihydrite based on pair distribution function analysis of X-ray total scattering. Chem. Mater. 19, 1489-1496.

Michel, F. M., MacDonald, J., Feng, J., Phillips, B. L., Ehm, L., Tarabrella, C., Parise, J. B., and Reeder, R. J. (2008). Structural characteristics of synthetic amorphous calcium carbonate. Chem. Mater. 20, 4720-4728.

Mikutta, C. (2011). X-ray absorption spectroscopy study on the effect of hydroxybenzoic acids on the formation and structure of ferrihydrite. Geochim. Cosmochim. Acta 75, 5122-5139.

Moyer, C. L., Dobbs, F. C., and Karl, D. M. (1994). Estimation of diversity and community structure through restriction fragment length polymorphism distribution analysis of bacterial 16S rRNA genes from a microbial mat at an active hydrothermal vent system, Loihi Seamount, Hawaii. Appl. Environ. Microbiol. 60, 871-879.

Moyer, C. L., Dobbs, F. C., and Karl, D. M. (1995). Phylogenetic diversity of the bacterial community from a microbial mat at an active, hydrothermal vent system, Loihi Seamount, Hawaii. Appl. Environ. Microbiol. 61, 1555-1562.

Murad, E., and Cashion, J. (2004). Mössbauer Spectroscopy of Environmental Materials and their Utilization. Boston: Kluwer.

Navrotsky, A., Mazeina, L., and Majzlan, J. (2008). Size-driven structural and thermodynamic complexity in iron oxides. Science 319 , 1635-1638.

O’Day, P. A., Rivera, N. Jr., Root, R., and Carroll, S. A. (2004). X-ray absorption spectroscopic study of Fe reference compounds for the analysis of natural sediments. Am. Mineral. 89, 572-585.

Penn, L. R. (2007). Resolving an elusive structure. Science 316, 1704-1705.

Penn, L. R., Erbs, J., and Gulliver, D. (2006). Controlled growth of alpha-FeOOH nanorods by 
exploiting oriented aggregation. J. Cryst. Growth 293, 1-4.

Percak-Dennett, E. M., Beard, B. L., $\mathrm{Xu}, \mathrm{H}$., Konishi, H., Johnson, C. M., and Roden, E. E. (2011). Iron isotope fractionation during microbial dissimilatory iron oxide reduction in simulated Archaean seawater. Geobiology 9, 205-220.

Pinney, N., Kubicki, J. D., Middlemiss, D. S., Grey, C. P., and Morgan, D. (2009). Density functional theory study of ferrihydrite and related Fe-oxyhydroxides. Chem. Mater. 21, 5727-5742.

Pokrovski, G. S., Schott, J., Garges, F., and Hazemann, J. L. (2003). Iron (III)-silica interactions in aqueous solution: insights from $\mathrm{X}$ ray absorption fine structure spectroscopy. Geochim. Cosmochim. Acta 67, 3559-3573.

Poulsen, H. F., Neuefeind, J., Neumann, H. B., Schneider, J. R., and Zeidler, M. D. (1995). Amorphous silica studied by high-energy X-raydiffraction. J. Non Cryst. Solids 188, 63-74.

Qiu, X., Thompson, J. W., and Billinge, S. J. L. (2004). PDFgetX2: a GUIdriven program to obtain the pair distribution function from X-ray powder diffraction data. J. Appl. Crystallogr. 37, 678.

Ravel, B., and Newville, M. (2005). Athena, Artemis, Hephaestus: data analysis for X-ray absorption spectroscopy using IFEFFIT. J. Synchrotron Radiat. 12, 537-541.

Rentz, J. A., Kraiya, C., Luther, G. W. III, and Emerson, D. (2007). Control of ferrous iron oxidation within circumneutral microbial iron mats by cellular activity and autocatalysis. Environ. Sci. Technol. 41, 6084-6089.
Rodmacq, B. (1984). Superparamagnetic properties of small iron hydroxide precipitates in ion exchange membranes. J. Phys. Chem. Solids 45, 1119-1127.

Rose, J., Flank, A.-M., Masion, A., Bottero, J. Y., and Elmerich, P. (1997). Nucleation and growth mechanisms of Fe oxyhydroxide in the presence of PO4 ions. 2. P K-edge EXAFS study. Langmuir 13, 1827-1834.

Schwertmann, U., Friedl, J., and Kyek, A. (2004). Formation and properties of a continuous crystallinity series of synthetic ferrihydrites (2- to 6-line) and their relation to $\mathrm{FeOOH}$ forms. Clays Clay Miner. 52, 221-226.

Sedwick, P. N., McMurtry, G. M., and MacDougall, J. D. (1992). Chemistry of hydrothermal solutions from Pele's Vents, Loihi Seamount, Hawaii. Geochim. Cosmochim. Acta 56, 3643-3667.

Silva, N. J. O., Amaral, V. S., Carlos, L. D., Rodríguez-Gonzáles, B., Liz-Marzán, L. M., Berquó, T. S., Banerjee, S. K., de Zea Bermudez, V., Millán, A., and Palacio, F. (2008). Evidence of random magnetic anisotropy in ferrihydrite nanoparticles based on analysis of statistical distributions. Phys. Rev. B 77, 1-6.

Sudek, L. A., Templeton, A. S., Tebo, B. M., and Staudigel, H. (2009). Microbial ecology of $\mathrm{Fe}$ (hydr)oxide mats and Basaltic Rock from Vailulu'u Seamount, American Samoa. Geomicrobiol. J. 26, 581-596.

Suzdalev, I. P., Buravtsev, V. N., Imshennik, V. K., Maksimov, Y. V., Matveev, V. V., Novichikhin, S. V., Trautwein, A. X., and Winkler, H. (1996). Magnetic properties of ultrafine ferrihydrite clusters studied by Mössbauer spectroscopy and by thermodynamical analysis. Z. Phys. D 37, 55-61.

Swedlund, P. J., Miskelly, G. M. and McQuillan, A. J. (2009). An attenuated total reflectance IR study of silicic acid adsorbed onto a ferric oxyhydroxide surface. Geochim. Cosmochim. Acta 73 4199-4214.

Templeton, A. S., Knowles, E. J., Eldridge, D. L., Arey, B. W., Dohnalkova, A. C., Webb, S. M., Bailey, J. V., Tebo, B. M., and Staudigel, H. (2009). A seafloor microbial biome hosted within incipient ferromanganese crusts. Nature Geoscience 2, 872-876.

Toner, B. M., Santelli, C. M., Marcus, M. A., Wirth, R., Chan, C. S., McCollom, T. M., Bach, W. and Edwards, K. J. (2009). Biogenic iron oxide formation at Mid-Ocean Ridge hydrothermal vents: Juan de Fuca Ridge. Geochim. Cosmochim. Acta 73, 388-403.

Vilge-Ritter, A., Rose, J., Masion, A., Bottero, J. Y., and Laine, J. M. (1999). Chemistry and structure of aggregates formed with Fe-salts and natural organic matter. Colloids Surf. A Physicochem. Eng. Asp. 147, 297-308.

Voegelin, A., Kaegi, R., Frommer, J., Vantelon, D., and Hug, S. J. (2010). Effect of phosphate, silicate, and $\mathrm{Ca}$ on $\mathrm{Fe}$ (III)-precipitates formed in aerated $\mathrm{Fe}$ (II)- and As(III)-containing water studied by X-ray absorption spectroscopy. Geochim. Cosmochim. Acta 74, 164-186.

Waychunas, G. A., Fuller, C. C., Rea, B. A., and Davis, J. A. (1996). Wide angle X-ray scattering (WAXS) study of "two-line" ferrihydrite structure: effect of arsenate sorption and counterion variation and comparison with EXAFS results. Geochim. Cosmochim. Acta 60, 1765-1781.

Webb, S. M. (2005). SIXPACK: a graphical user interface for XAS analysis using IFEFFIT. Phys. Scr. T115, 1011-1014.

Webb, S. M. (2006). Sam's Microprobe Analysis Tool Kit. Available at: http://smak.sams-xrays.com/

Wheat, C. G., Jannasch, H. W., Plant, J. N., Moyer, C. L., Samsone, F. J., and McMurtry, G. M. (2000). Continuous sampling of hydrothermal fluids from Loihi Seamount after the 1996 event. J. Geophys. Res. 105, 19353-19367.

Conflict of Interest Statement: The authors declare that the research was conducted in the absence of any commercial or financial relationships that could be construed as a potential conflict of interest.

Received: 22 November 2011; paper pending published: 27 December 2011; accepted: 12 March 2012; published online: 02 April 2012.

Citation: Toner BM, Berquó TS, Michel FM, Sorensen JV, Templeton AS and Edwards KJ (2012) Mineralogy of iron microbial mats from Loihi Seamount. Front. Microbio. 3:118. doi: 10.3389/fmicb.2012.00118

This article was submitted to Frontiers in Microbiological Chemistry, a specialty of Frontiers in Microbiology.

Copyright (C) 2012 Toner, Berquó, Michel, Sorensen, Templeton and Edwards. This is an open-access article distributed under the terms of the Creative Commons Attribution Non Commercial License, which permits non-commercial use, distribution, and reproduction in other forums, provided the original authors and source are credited. 


\section{APPENDIX}

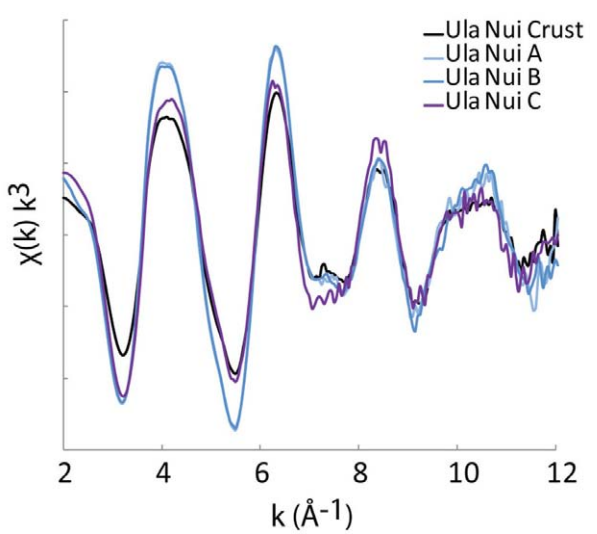

FIGURE A1 | Iron K-edge EXAFS spectra for the Ula Nui mats of Loihi Seamount having different sample handling and data collection conditions. The Ula Nui Crust was stored and analyzed frozen under $\mathrm{N}_{2}$ at an SSRL microprobe beamline in fluorescence mode. Ula Nui-A/B were stored frozen, thawed, rinsed, and dried at $40^{\circ} \mathrm{C}$ with analysis at the APS at a bulk beamline in transmission mode. Ula Nui $\mathrm{C}$ was stored in ambient seawater at $4^{\circ} \mathrm{C}$ for 6 months, and was analyzed as rinsed/air-dry particles at an ALS microprobe beamline in fluorescence mode.

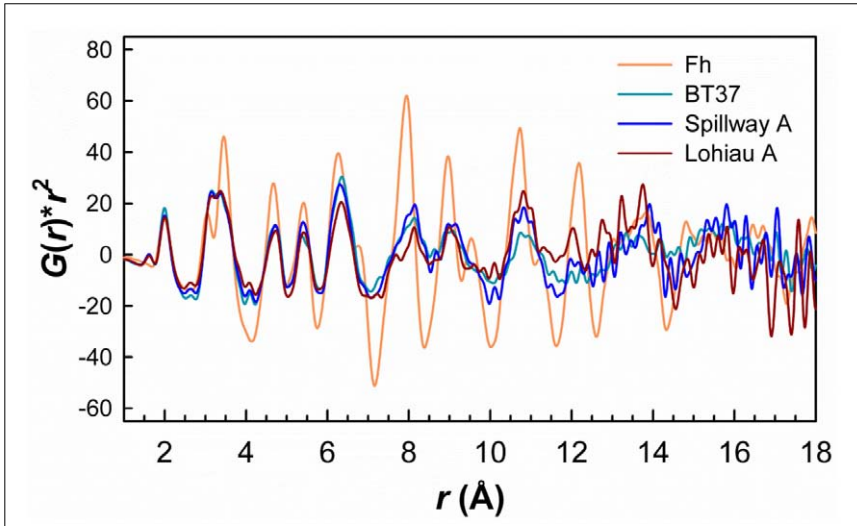

FIGURE A3 | Comparison of PDFs for BT37, Spillway A, and Lohiau A to the Fh reference plotted as $G(r)^{*} r^{2}$ versus $r$ to amplify the features at higher $\boldsymbol{r}$ values. Although subtle for the natural samples the features $>\sim 4 \AA$ are reasonable similar to those of synthetic Fh. Note that the PDF for Fh was also multiplied by 0.25 for comparison. Ula Nui-A and -B also showed similar features but due to impurities (e.g., birnessite) were excluded for clarity.

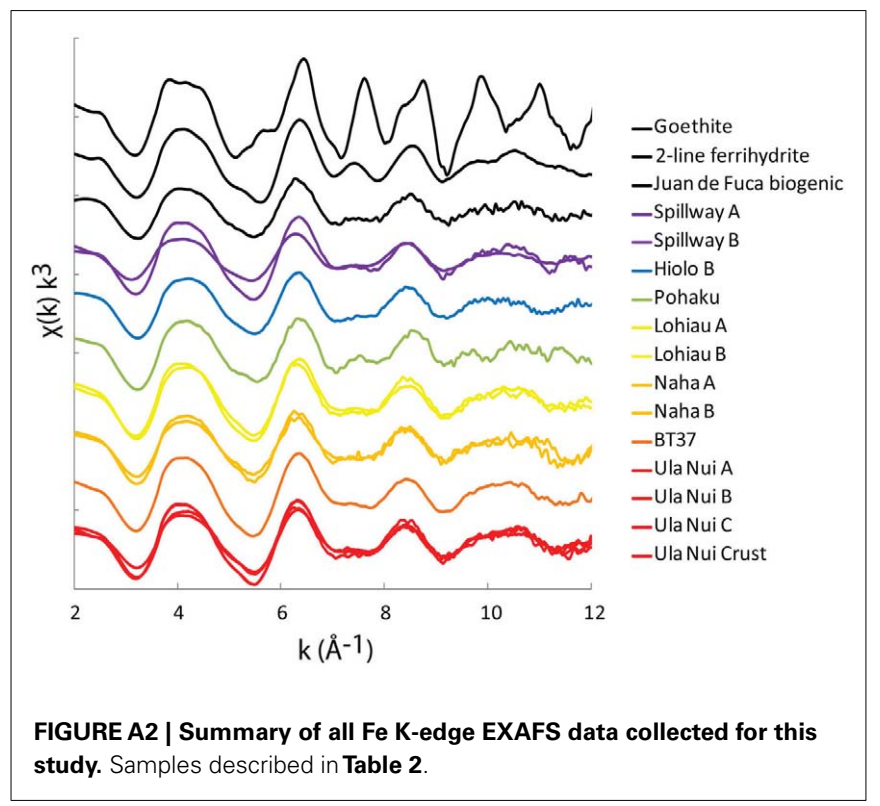

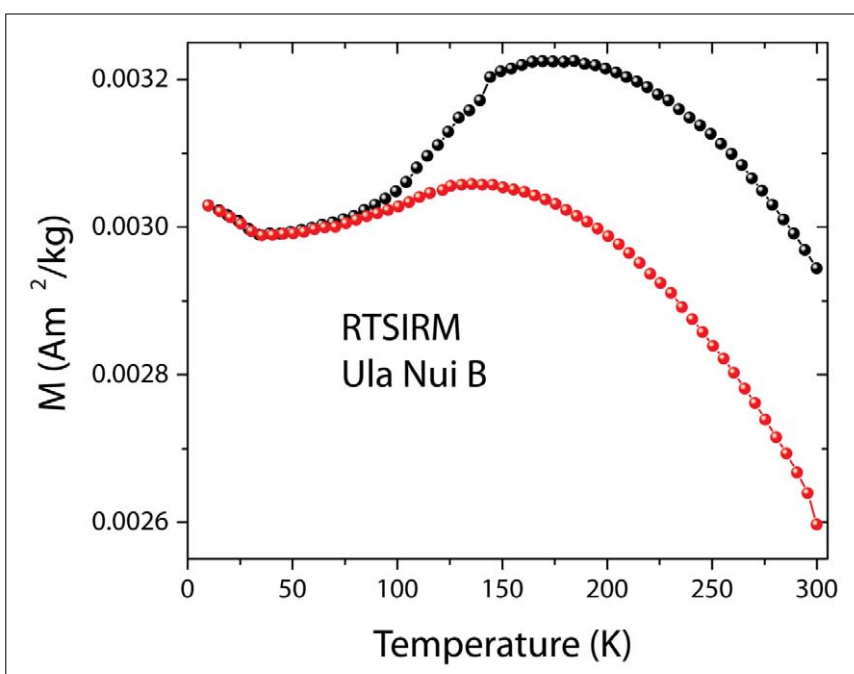

FIGURE A4 |The RTSIM shows the typical behavior associated with the presence of Ti-magnetite. The curves obtained on cooling (black circles) and on warming (red circles) are displayed. Due to its high magnetization, magnetite can be observed in the mats at very low concentrations. 